\title{
Historical development of vaginal microbicides to prevent sexual transmission of HIV in women: from past failures to future hopes
}

This article was published in the following Dove Press journal:

Drug Design, Development and Therapy

I5 June 2017

Number of times this article has been viewed

\section{Fernando Notario-Pérez \\ Roberto Ruiz-Caro \\ María-Dolores Veiga-Ochoa}

Department of Pharmacy and Pharmaceutical Technology, School of Pharmacy, Universidad Complutense de Madrid, Madrid, Spain
Correspondence: María-Dolores Veiga-Ochoa

Department of Pharmacy and Pharmaceutical Technology, School of Pharmacy, Universidad Complutense de Madrid, Plaza de Ramón y Cajal

s/n, 28040 Madrid, Spain

Tel +34 9l 394209 |

Fax+349I394 1736

Email mdveiga@ucm.es
Abstract: Infection with human immunodeficiency virus (HIV) remains a global public health concern and is particularly serious in low- and middle-income countries. Widespread sexual violence and poverty, among other factors, increase the risk of infection in women, while currently available prevention methods are outside the control of most. This has driven the study of vaginal microbicides to prevent sexual transmission of HIV from men to women in recent decades. The first microbicides evaluated were formulated as gels for daily use and contained different substances such as surfactants, acidifiers and monoclonal antibodies, which failed to demonstrate efficacy in clinical trials. A gel containing the reverse transcriptase inhibitor tenofovir showed protective efficacy in women. However, the lack of adherence by patients led to the search for dosage forms capable of releasing the active principle for longer periods, and hence to the emergence of the vaginal ring loaded with dapivirine, which requires a monthly application and is able to reduce the sexual transmission of HIV. The future of vaginal microbicides will feature the use of alternative dosage forms, nanosystems for drug release and probiotics, which have emerged as potential microbicides but are still in the early stages of development. Protecting women with vaginal microbicide formulations would, therefore, be a valuable tool for avoiding sexual transmission of HIV.

Keywords: vaginal formulations, microbicides, prevention, sexual transmission, acquired immunodeficiency syndrome (AIDS), human immunodeficiency virus (HIV)

\section{Introduction}

Acquired immunodeficiency syndrome (AIDS) is a global health concern. It is a chronic infectious disease caused by the human immunodeficiency virus (HIV), an enveloped virus in the Retroviridae family with a lipid membrane and is capable of interacting with $\mathrm{CD}^{+} \mathrm{T}$ cells, thanks to gp120. The virus infects the cells of the immune system, destroying or impairing their function and causing a progressive deterioration of the immune system until the sufferer falls into an immunodeficient state. Primary HIV infection is symptomatic in over half the reported cases, but may be overlooked as the symptoms resemble those of a common viral infection. There are two serotypes of the virus (HIV-1 and HIV-2), whose key difference in functional terms is that in HIV-2 infection, the amount of circulating viruses is lower than in HIV-1 infection, making its evolution slower and incubation period longer. Nevertheless, both serotypes ultimately cause AIDS. ${ }^{1}$ AIDS is the most advanced stage of HIV infection, in which the immune system ceases to respond effectively and diseases develop due to the loss of the body's defense capability. ${ }^{2}$ 
Table I Classification of antiretroviral drugs

\begin{tabular}{ll}
\hline Mechanism of action & Drugs \\
\hline Entry inhibitors or Fls & Enfuvirtide, maraviroc \\
NRTIs & Tenofovir, adefovir, zidovudine, didanosine, \\
& stavudine, emtricitabine, abacavir, lamivudine \\
NNRTIs & Efavirenz, rilpivirine, nevirapine, dapivirine \\
& or etravirine \\
Pls & Ritonavir, darunavir \\
Ils & Dolutegravir, raltegravir
\end{tabular}

Abbreviations: Fls, fusion inhibitors; Ils, integrase inhibitors; NRTIs, nucleoside reverse transcriptase inhibitors; NNRTIs, non-nucleoside reverse transcriptase inhibitors; Pls, protease inhibitors.

The goal of ending the AIDS epidemic is becoming more attainable through the elimination of HIV transmission and AIDS-related deaths, ${ }^{3,4}$ which is now possible thanks to the numerous antiretroviral drugs with different mechanisms of action currently available for the treatment of HIV (Table 1). These drugs are able to inactivate the virus at different stages of the viral cycle (Figure 1).

However, stigma and discrimination, violence against women and girls and unjust laws continue to hamper efforts to achieve global targets. If these challenges can be overcome, and if efforts to prevent HIV continue to gain in efficacy and with the rapid rise in the number of people receiving treatment - the world will attain its goal of ending the AIDS epidemic in the not-too-distant future.

The seventh objective set by the United Nations for bringing an end to AIDS specifically raises the question of the current status of women - particularly in low- and middleincome countries - in terms of protection against HIV, since the likelihood of transmission of sexually transmitted infections (STIs) from men to women has been observed to be alarmingly high. ${ }^{5}$

This is because current methods of preventing STIs, such as abstinence, condoms and monogamy, are often ineffective and outside the control of women; many men oppose the use of condoms and women do not have the authority to insist

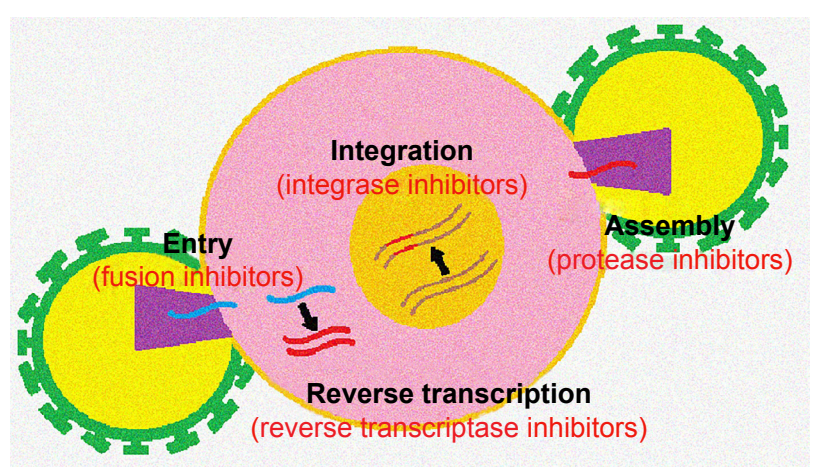

Figure I Targeting site of antiretroviral drugs at different stages of the viral cycle. that their partners use them. Thus, today, over $50 \%$ of new HIV infections are in women.

Sexual behavior is more likely to be the cause of STI transmission in certain countries, and there are indications that unsafe sex has increased in several nations. The latest data point to a significant rise in polygamy in a number of countries (Burkina Faso, Congo, Ivory Coast, Ethiopia, Gabon, Guyana, Rwanda, South Africa, Uganda, Tanzania and Zimbabwe) as well as a decline in condom use (Ivory Coast, Niger, Senegal and Uganda). ${ }^{5}$

The main setbacks to efforts to prevent HIV transmission are the lack of access to sexual education services and sexual violence against young women and girls. Each year, about 380,000 women aged between 10 and 24 years suffer from HIV infection, meaning that 50 young women become infected with HIV every hour. Furthermore, $80 \%$ of women aged 10-24 with HIV live in sub-Saharan Africa. ${ }^{6}$

It is, therefore, necessary to have female-controlled methods such as microbicides that may be used to prevent vaginal acquisition of HIV.

Microbicides are currently seen as a promising tool to protect women from acquiring this type of infection. The use of microbicides is be controlled by women, who can apply them before intercourse without the man's cooperation. A vaginal microbicide can be defined as any agent included in a topical formulation designed to prevent the spread of sexually transmitted pathogens either through cell death, inactivation of cell mechanisms, inhibition of viral replication, the formation of a physical barrier between cells and pathogens, or by enhancing the natural protection mechanisms of the cervix and vagina. ${ }^{?}$

Unfortunately, many vaginal microbicide formulations may fail to produce a protective effect due to their lack of efficacy and their unsuitable formulation. ${ }^{8}$ Some of the most frequently used vaginal dosage formulations include creams, gels, ${ }^{9-13}$ tablets, ${ }^{14}$ films ${ }^{15}$ and intravaginal rings, ${ }^{16-18}$ each of which has particular advantages and drawbacks.

In view of the above, there is little doubt that the development of a safe, effective and affordable vaginal microbicide that is easy to manufacture, stable under different environmental conditions and comfortable for women to administer themselves would represent a major breakthrough in preventing HIV transmission.

\section{Historical development of vaginal microbicides}

In recent decades, very different strategies have arisen to prevent the sexual transmission of HIV. According to their mechanism of action, we can distinguish microbicides 
without antiretroviral drugs, such as surfactants, polyanions, acidifiers and gp120 neutralizing monoclonal antibodies, and microbicides-containing drugs used for HIV treatment, for example, entry inhibitors or inhibitors of viral enzymes. These microbicides can inhibit virus transmission at different sites: while the virus is in the vaginal environment, it can be inactivated by microbicides containing surfactants, polyanions or monoclonal antibodies, or due to acidic $\mathrm{pH}$ achieved with the use of acidifiers; or, once HIV has passed through the vaginal epithelium, it can be prevented from internalizing in $\mathrm{CD}^{+} \mathrm{T}$ cells by entry inhibitors, or else, viral replication can be prevented with reverse transcriptase inhibitors (Figure 2). However, after years of research with different potential microbicide substances, the current trend is toward the development of microbicides with antiretroviral drugs such as maraviroc (MVC) (ViiV Healthcare, Brentford, United Kingdom), tenofovir (TFV) (Gilead Sciences, Cambridge, United Kingdom) or dapivirine (DPV) (IPM, Silver Spring, MD, USA), which have offered the most promising results in clinical trials.

\section{First attempts to prevent sexual transmission of HIV: vaginal gels}

Gels are possibly the most widely studied pharmaceutical formulations for developing vaginal microbicides. They were the pharmaceutical dosage form of choice for the first vaginal microbicides, possibly because they have the advantage of being easily and conveniently applicable by women, which makes the use of such formulations greatly improve adherence to treatment. ${ }^{19}$ In addition, their manufacturing cost is not very high, especially compared to more sophisticated forms, and they are easy to mass produce. Gels are optimal formulations for ensuring the microbicide begins to exert its action quickly; however, they are generally unable to retain the drug and provide sustained release over time. They also require certain conditions of conservation, as they are not particularly stable against adverse environmental conditions.

\section{Surfactants, the first failure}

Surfactants such as nonoxynol-9 or Savvy gel ${ }^{\circledR}$ were the first substances evaluated as microbicides. They act as a virucide by lowering the surface tension of the pathogen, resulting in the death of the microorganism before it comes into contact with the vaginal mucosa. ${ }^{20,21}$ However, the lack of effective protection for women highlighted by the studies led to the rapid rejection of the use of surfactants in microbicide formulations. ${ }^{20-23}$ This was not all; tests showed that not only is nonoxynol-9 ineffective in preventing HIV transmission, but also it increases the incidence of genital lesions such as vaginal ulcers, thus raising the risk of STIs. ${ }^{20,24}$

\section{Screening of alternative substances: acidifiers, polyanions, monoclonal antibodies and entry inhibitors}

After the failure of surfactants, new strategies to develop vaginal microbicides turned toward mechanisms that work by preventing the pathogen from entering the cells. The most

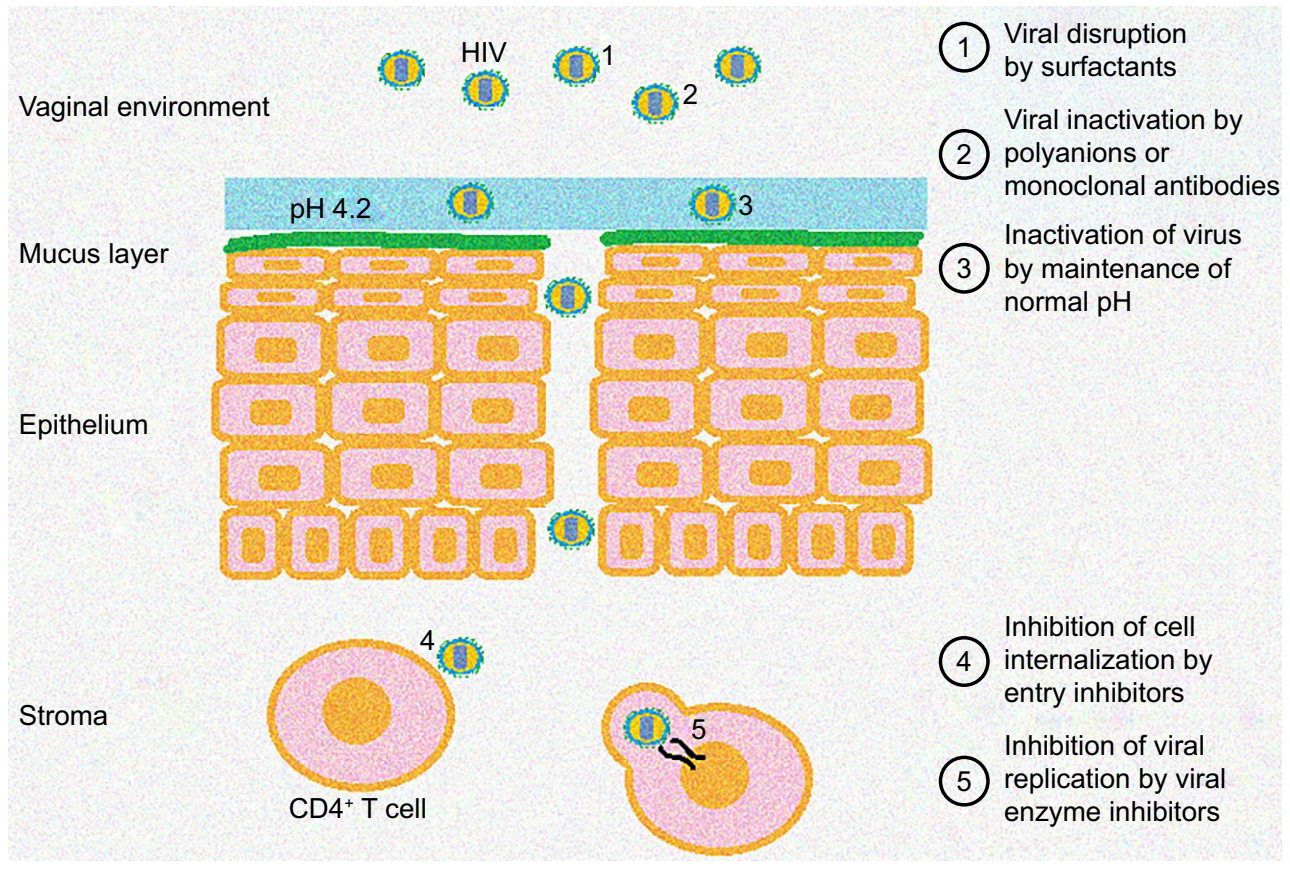

Figure 2 Diagram of the action sites of different microbicides against HIV. 
basic formulations simply prevent contact between the surface of the vaginal mucosa and pathogens.

Carraguard $^{\circledR}$ is a gel under research whose active ingredient is carrageenan, a sulfated linear polysaccharide extracted from seaweed. The microbicide was formulated as a gel to be applied to the vaginal mucosa in the hour prior to sexual intercourse. ${ }^{25}$ Studies have shown that its use is safe for women, and the associated side effects are mild and infrequent. ${ }^{26,27}$ This gel also proved its ability to reduce the risk of sexual transmission of human papillomavirus. ${ }^{28}$ However, Phase II trials failed to show efficacy in preventing HIV transmission. ${ }^{25,29,30}$ The use of the gel is currently being assessed as a carrier of an antiretroviral drug. ${ }^{25}$

Another mechanism designed to prevent the entry of pathogens into the cells was the use of acidifiers such as BufferGel $^{\circledR}$. This acidifier acts as a buffer and is capable of maintaining normal vaginal acidity in the presence of ejaculated semen. This microbicide is based on studies suggesting that an acidic environment could inhibit HIV. ${ }^{31}$ However, although studies on BufferGel have shown it to be safe, it has not demonstrated effectiveness in preventing HIV transmission. ${ }^{32,33}$

The lack of efficacy of these strategies prompted the search for a very diverse range of substances capable of interacting directly with the virus, ${ }^{34}$ from polyanions or monoclonal antibodies able to recognize the HIV and bind to it to antiretroviral drugs that act as fusion inhibitors, such as MVC.

One example of the gels tested as a means of blocking the pathogen is PRO 2000, whose active ingredient is the synthetic polymer naphthalene sulfonate. This is a negatively charged polyanion capable of interacting with the positive charges of viral gp120 to block virus entry into cells. ${ }^{35}$ It has proven antiviral activity against HIV-1 in vitro and in animal models, and a favorable risk profile..$^{33,36,37}$ Nevertheless, although trials in women have demonstrated high adherence and safety, it has no demonstrated effectiveness in preventing sexual transmission of HIV. 33,37

VivaGel ${ }^{\circledR}$ is another polyanion currently under study, whose active ingredient is SPL7013, a dendrimer expressly created using nanotechnology to show antiviral activity against $\mathrm{HIV},{ }^{38}$ and is formulated in a mucoadhesive carbopol gel. ${ }^{39}$ It has shown antiviral activity against HIV in the presence of seminal plasma, ${ }^{40}$ as well as in animal models, ${ }^{38,41}$ along with good tolerance in animals and humans..$^{38,42-44}$ However, subsequent clinical trials revealed adverse effects associated with this formulation, leading to its rejection on the grounds of being unsafe for continued use in women. ${ }^{45,46}$
A further study confirmed the inefficacy of polyanions in clinical trials despite their in vitro efficacy. This ineffectiveness was due to the formation of a semen-derived enhancer of virus infection, which promoted HIV infection in the presence of semen..$^{47,48}$ Although Sonza et al reported that this enhancement effect is not applicable to all polyanions, ${ }^{49}$ it highlighted the importance of performing the effectiveness tests in the presence of semen.

Some microbicidal formulations also include gp120neutralizing monoclonal antibodies, which recognize and bind to the viral gp120, thus preventing the virus from binding to $\mathrm{CD}^{+}{ }^{+} \mathrm{T}$ lymphocytes. Examples include vitamin $\mathrm{B}_{12}$ and the monoclonal antibodies $2 \mathrm{G} 12$ and PRO- $140 . .^{50-53}$

Other agents with the ability to bind to gp120 are lectins. ${ }^{54}$ The lectin most widely studied for its ability to bind HIV is probably CV-N, a protein from cyanobacteria capable of potently inactivating HIV-1, HIV-2 and simian immunodeficiency virus by binding irreversibly to gp 120 . Research into this active ingredient has proved its effectiveness in blocking infection by HIV-1 in ectocervical human explants. ${ }^{55}$ It was formulated in $1 \%$ and $2 \% \mathrm{CV}-\mathrm{N}$ gels, and in all cases showed protection against the virus in monkeys without any adverse or cytotoxic effect. ${ }^{56} \mathrm{CV}-\mathrm{N}$ could, therefore, be a good candidate for human trials as a topical microbicide against HIV. In order to reduce the high cost of its production, efforts have been made to develop transgenic plants capable of producing CV-N, achieving positive results in rice endosperm, Nicotiana tabacum and soybean seeds. ${ }^{57-59}$ Griffithsin, a protein from red seaweeds, is another drug with the same mechanism of action. Studies to date are encouraging, as they have demonstrated its activity in picomolar concentrations and absence of irritability and inflammation. ${ }^{60,61}$ It has also been successfully expressed and purified from transgenic plants, which would make it more economical. ${ }^{60,62-64}$ Although it has yet to be tested in animals, it already has proven features that represent a significant step forward in the development of vaginal microbicides based on gp120-neutralizing monoclonal antibodies, as it would solve the main problems found during experimentation with other active ingredients in this family, namely, the need for high concentrations and the high production costs. ${ }^{60,62}$

Finally, it is worth mentioning microbicides that contain entry inhibitors such as MVC, an approved antiretroviral drug for treatment of HIV-1 CCR5-tropic in adults. ${ }^{65}$ It is specifically an antagonist of the CCR5 receptor, a protein located in T lymphocytes, which binds to HIV at the time of cell entry. MVC binds to these receptors and prevents HIV 
from infecting cells and multiplying. However, this drug is not active in all patients, as in some subjects, the virus uses another receptor called CXCR4 to enter the cells. ${ }^{66}$

There are several studies aimed at testing the efficacy of MVC as a microbicide, which have proven its efficacy even in the presence of semen ${ }^{48,67}$ and its tendency to concentrate in the cervicovaginal fluid and vaginal tissue. ${ }^{68}$ One of these trials assessed the efficacy of a topical vaginal gel of hydroxyethyl cellulose containing 2.2\% MVC in humanized mouse strains (RAG-hu). The gel was applied to female mice before exposing them vaginally 1 hour later to HIV-1, in order to compare its protective efficacy versus the placebo gel; no mouse was infected with the virus, while those treated with the placebo were. ${ }^{69}$

Another trial with this active ingredient studied the effectiveness of a hydroxyethyl cellulose gel with different concentrations of MVC in macaques, where it was found that complete protection was achieved against the virus with the gel with 3.3\% MVC. However, this protection could only be achieved with a high concentration in the vaginal fluid, which was only attained between 30 minutes and 2 hours after the administration of the gel. Protection, therefore, largely depends on the time elapsed between application and contact with the virus. ${ }^{70,71}$

Following these assays, several studies have sought to lengthen the residence time of the gel. One proposed formulation tested in macaques was a silicone gel with $\mathrm{MVC}^{72}$ compared to a hydroxyethyl cellulose gel with the same load of MVC, which achieved greater and more sustained MVC concentrations in the vaginal fluid. ${ }^{73}$

\section{Inclusion of viral enzyme inhibitors: first positive results}

Although, as we have seen, the initial trend in the search for an effective microbicide was to use substances to prevent the entry of the virus in order to block the first step of infection, ${ }^{74}$ after unsuccessfully evaluating numerous compounds in clinical trials, the focus switched to the study of potential microbicides with antiretroviral drugs that prevent virus replication. ${ }^{75}$

Nucleoside reverse transcriptase inhibitors (NRTIs) were the first antiretroviral drugs to show activity against HIV. Several drugs in this family are used today to treat HIV patients and are being studied as potential microbicides. Possibly, the most widely studied drug in this group is TFV, which acts in the case of HIV infection by blocking the activity of reverse transcriptase and preventing the virus from infecting cells and replicating. ${ }^{76,77}$
Although the antiretroviral activity of TFV has been confirmed and it has been approved for oral use, research is required into its potential microbicidal effect against HIV, in addition to efficacy and safety studies, before vaginal pharmaceutical forms with this active ingredient can be developed. TFV microbicide formulations have proven antiviral efficacy in vitro ${ }^{78}$ and in animal models, ${ }^{79,80}$ and have been evaluated in Phase III clinical trials. Studies with a TFV-based vaginal gel have shown it has no significant cytotoxicity in women. ${ }^{81-83}$ Finally, several safety studies with this microbicide indicate that TFV has no toxicity for vaginal mucosa at concentrations commonly used as a microbicide. ${ }^{11,18,84}$ It has also proven to be acceptable and well tolerated by women. ${ }^{81,85,86}$

The CAPRISA 004 study evaluated the effectiveness of a $1 \%$ TFV gel in preventing HIV transmission in South African women. ${ }^{87}$ The gel was found to reduce HIV infection by $39 \%$ and even 54\% when women had high adherence to treatment. ${ }^{87,88}$

Following the successful CAPRISA 004 study, numerous further projects sought to reproduce the TFV gel. The MTN-001 study compared the use of a TFV gel with the oral administration of this drug, and found that higher concentrations of the drug could be achieved in the vaginal tissue with vaginal administration. ${ }^{89}$ The same study also demonstrated lower adherence to microbicides in sub-Saharan Africa compared to the USA. ${ }^{90}$ More recent studies have confirmed the effectiveness of the gel; ${ }^{91}$ but in the VOICE trial, using a $1 \%$ TFV gel in African women was not observed to reduce the likelihood of HIV infection, although adherence to treatment was low. ${ }^{10}$

Although the recent negative results of some tests are puzzling, ${ }^{91}$ evidence supports the efficacy of this antiretroviral in preventing the transmission of HIV-1, ${ }^{88,92,93}$ offering a cost-effective method that can be controlled by women. ${ }^{94,95}$ The success of the TFV gel was a milestone in the development of an effective vaginal microbicide to prevent sexual transmission of HIV.$^{93,96}$

However, the clinical trials with this gel also served to highlight the importance of analyzing the different parameters that could influence its efficacy. ${ }^{96}$ According to the results of the clinical trials, adherence is the key factor in achieving protection. ${ }^{97-100}$ Other factors influencing its effectiveness include adhesion of the formulation to the mucosa, which could alter the drug concentration and the integrity of the vaginal mucosa,${ }^{97}$ and the time elapsed between gel application and sexual intercourse. ${ }^{101}$ Another factor that has been shown to be important in the efficacy of the 
formulation is systemic innate immune activation prior to infection; one possible mechanism to increase the efficacy of the TFV gel is the addition of a suppressor of innate immune system activation. ${ }^{102}$

Another family of antiretroviral drugs consists of non-nucleoside reverse transcriptase inhibitors (NNRTIs). These are noncompetitive inhibitors that bind to an allosteric site on the reverse transcriptase and induce conformational changes in the enzyme. ${ }^{103}$ Various NNRTIs have been studied as microbicides, including DPV and rilpivirine, ${ }^{104-106}$ and multiple NNRTIs have been specifically designed with the ability to bind more closely to HIV-1 retrotranscriptase, such as MIV-150, a derivate of urea-phenethylthiazolylthiourea, ${ }^{65,103}$ and UC78, a thiocarboxanilide. ${ }^{103}$

Several studies have been carried out in macaques using different pharmaceutical forms containing MIV-150, an example of which is the combination of MIV-150 with Carraguard. ${ }^{107}$ As previously described, Carraguard is a carrageenan gel that showed no efficacy in clinical trials, but has been assessed as a vehicle for antiretroviral drugs in the development of vaginal microbicides. ${ }^{25}$ In vitro assays demonstrated greater antiretroviral activity of the MIV-150/ carrageenan combination compared to Carraguard, and this efficacy was not modified by the presence of seminal fluid. ${ }^{107}$ However, in vivo assays with this combination ruled out its potential as a microbicide due to the predominance of the barrier effect of Carraguard, which prevented the combination with MIV-150 from being more effective. ${ }^{108}$ Nevertheless, the MIV-150 in the placebo gel limited vaginal infection, confirming the potential of topical NNRTIs in preventing sexual transmission of HIV. ${ }^{108}$ Another gel combining MIV150 and zinc acetate showed protection in animal models against simian-human immunodeficiency virus (SHIV) for 24 hours after vaginal administration, improving the protection achieved when the gel contained only one of the agents. ${ }^{109,110}$ The MIV-150/zinc acetate/Carraguard combination (MZC) was also evaluated, and was found to provide significant protection in macaques with its pre- and postcoital application. ${ }^{110-114}$ An in vitro study comparing the efficacy of MZC gel versus 1\% TFV gel showed increased activity against SHIV-retrotranscriptase with MZC gel. ${ }^{115}$ After the promising data shown by this formulation, the first clinical trials were eagerly awaited. The results of the first clinical trial with MZC gel have recently been published, showing that the gel is safe and well tolerated by women. ${ }^{116}$

DPV is a much studied drug in this group, and has undergone clinical trials as one of the most promising drugs for the development of microbicides to prevent HIV-1 transmission.
The studies have demonstrated its in vitro activity to prevent infection even in the presence of semen, ${ }^{117}$ and further trials in animal models showed that DPV does not irritate the vagina. ${ }^{118}$ Gels containing this antiretroviral were formulated and evaluated in animal models, and a high concentration of DPV was found in the vaginal tissue after administration. ${ }^{119}$ The first clinical trials with DPV gel were subsequently performed, demonstrating that its administration is safe and well tolerated by both women ${ }^{120-122}$ and men. ${ }^{123}$ Another finding was that much higher concentrations were achieved with the vaginal release of DPV from the gel than were required to achieve HIV inhibition in vitro. ${ }^{121}$

However, the effectiveness of drugs from this family must be evaluated in women, and especially in continuous prophylactic use, as their main drawback is the rapid development of HIV resistance to these drugs. ${ }^{124}$

\section{Trend change in microbicide formulation: development of vaginal rings}

Although the results obtained in recent years with gels containing reverse transcriptase inhibitors increase the hope of developing a microbicide that will significantly reduce HIV transmission, the creation of an effective vaginal microbicide also implies knowledge of the circumstances of the target population, and transmission prevention strategies must be adapted accordingly. ${ }^{125}$ This is why much of the current effort focuses on understanding the aspects that govern the effectiveness of microbicides, among which a key factor is considered to be adherence in trials. Strategies must, therefore, be designed to improve adherence and the factors that influence it. These range from supporting the users, assessing their perception of risk and analyzing their social background and relationship problems, including whether or not their partners allow them to use microbicides. As a result, attention has shifted toward the development of formulations that require less commitment from the user to show efficacy, such as sustained drug release formulations. ${ }^{126,127}$ Since adherence to treatment has been seen as a crucial factor, sustained-release formulations of antiretrovirals, such as vaginal rings, may lead to increased adherence, requiring less frequent application to achieve the necessary efficacy to avoid transmission. ${ }^{127-129}$

Vaginal rings could, therefore, represent a real alternative, as although they require a higher financial investment and are more complicated to manage, they have the advantage of allowing the sustained release of the drug over time periods of almost a month. ${ }^{130,131}$ The increase in cost could be significantly offset by the decrease in the number of 
applications and the subsequent improvement in adherence to treatment. The mass production of this dosage form is becoming increasingly advanced.

Since TFV has been the only vaginal microbicide to date to demonstrate protective efficacy in clinical trials, a wide range of formulations emerged that sought to improve the initial design in order to achieve effective microbicides that provide greater benefit than $1 \%$ TFV gel. ${ }^{132}$

Silicone ${ }^{133}$ and polyurethane ${ }^{134}$ rings containing TFV were formulated, and were able to release the drug for 25-30 days in the in vitro assays. In vivo assays with silicone rings on macaques demonstrated the safety of the formulation, as no adverse effects were observed, and they provided sustained release of TFV for $>28$ days. ${ }^{135}$ The polyurethane-based rings were studied in sheep, where a good safety profile was also observed, with the drug release up to 90 days in this case. ${ }^{132}$

As an alternative formulation, vaginal rings were also developed with tenofovir disoproxil fumarate (TDF), a prodrug of TFV (Figure 3). The in vitro models showed that TDF can inhibit HIV at concentrations hundreds of times lower than TFV, and maintain its antiviral activity in the presence of semen. ${ }^{136}$ The efficacy of intravaginal rings loaded with TDF was tested in female macaques versus placebo, where the rings showed complete protection against repeated exposure to the virus in the form of weekly exposure for 16 weeks. ${ }^{137}$ In a similar study, macaques were exposed to the virus vaginally once a week for 12 weeks. All the monkeys treated with the placebo were infected, but only one of the six that received the TDF-loaded ring was infected. ${ }^{17}$ These results indicate that the TDF ring provides lasting protection even against repeated exposure to the virus. Continuous-use trials of the formulation also showed that following continuous 6-month administration of these rings in macaques, the TFV levels in vaginal tissues and secretions remained constant and no adverse effects were observed. ${ }^{16}$

Given the excellent results in the animal tests, clinical trials were begun with TDF rings. It has recently emerged from the results of the Phase I trials that their use is safe

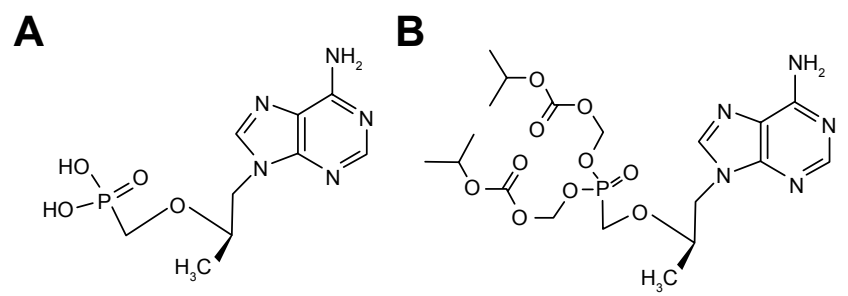

Figure 3 Chemical structure of tenofovir $(\mathbf{A})$ and tenofovir disoproxil fumarate (B). and well tolerated by women, and that TFV concentrations in the vaginal mucosa from the ring are capable of offering protection against HIV. ${ }^{138}$

Leveraging the intravaginal ring as an excellent vehicle for multiple drug administration, the combination of TFV and acyclovir was also evaluated to prevent the transmission of the herpes simplex virus, ${ }^{133}$ or with the addition of levonorgestrel to devise a ring that protected against HIV transmission and also had a contraceptive effect. ${ }^{139}$

TFV was not the only drug assessed for use in microbicidal vaginal rings. Another study on the same subject was designed to obtain sustained-release dosage forms of entry inhibitors. This involved pharmacokinetic studies with silicone elastomer vaginal rings containing MVC or CMPD167, two CCR5 receptor inhibitors, which release the active substances in a controlled manner over 28 days. The study showed that in macaques, this formulation could achieve vaginal fluid concentrations of above the inhibitory concentration in $50 \%$ of cases $\left(\mathrm{IC}_{50}\right)$ for both drugs, although the concentration of MVC was significantly higher than in the case of CMPD167. ${ }^{140}$

However, vaginal rings containing NNRTIs are the most widely studied for preventing the sexual transmission of HIV. The antiretroviral MIV-150 was initially the most commonly used, probably due to the results obtained with the gel. ${ }^{141-143}$ An intravaginal ring loaded with MIV-150 demonstrated significant protection against SHIV infection in macaques. ${ }^{141}$ As in the MIV-150 gel, the drug was subsequently evaluated in association with zinc acetate and carrageenan in order to improve the protection offered and reduce the dose of MIV-150, with a view to minimize its toxicity, the development of resistances and the cost of the formulation. These rings demonstrated their ex vivo effectiveness in monkey genital mucosa. ${ }^{144}$

Other NNRTIs evaluated for the development of vaginal rings are MIV-160, ${ }^{145} \mathrm{UC} 781^{146,147}$ and MC1220. ${ }^{148}$ The efficacy of the vaginal ring with MIV-160 was compared with a carrageenan gel containing the same drug, but efficacy was observed only with the vaginal ring when the two dosage forms were assessed in vitro, highlighting the importance of choosing the appropriate formulation for the development of vaginal microbicides. ${ }^{145}$ Poorer results were observed when evaluating UC781 in macaques, as no in vivo correlation was observed with the data obtained in vitro studies due to the poor solubility of the drug. ${ }^{147}$ In the case of rings containing the drug MC1220, only partial protection against HIV infection was observed in studies with macaques. ${ }^{148}$ 


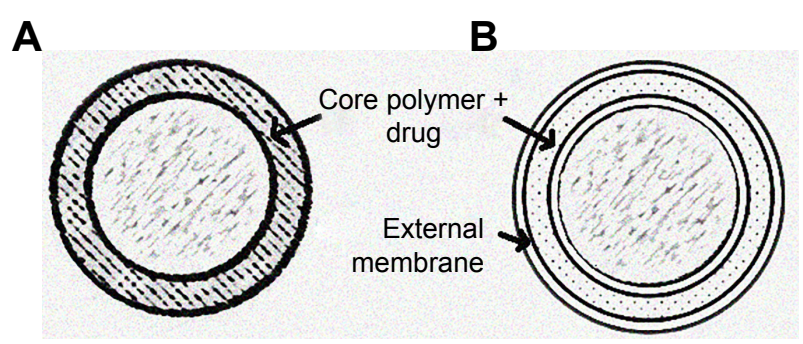

Figure 4 Structure of a matrix type (A) and reservoir type (B) vaginal ring.

Based on the results to date, undoubtedly, the most successful drug for use in vaginal rings to protect against sexual acquisition of HIV is another NNRTI, DPV. Vaginal rings were developed that were capable of releasing DPV in a sustained manner for 28-30 days. The materials used in their manufacture (polyurethane, silicone and others) and the type of ring (reservoir type or matrix type) were also assessed to obtain information about their impact on the effectiveness of the formulation (Figure 4). ${ }^{149,150}$ Various safety trials were conducted in women with vaginal rings loaded with DPV, all of which showed safety and good tolerance, in addition to controlled drug release for 28 days, and the ability to obtain far greater DPV concentrations in the genital tract than in the case of $\mathrm{IC}_{50}$ against HIV-1. ${ }^{151-154}$

These excellent results led to the DPV rings undergoing Phase III clinical trials, the furthest stage for any microbicide containing an NNRTI. The ASPIRE Phase III study evaluated the efficacy of a silicone matrix ring containing DPV in African women. ${ }^{155}$ Recent results from this study have shown that the DPV ring reduces HIV infection by $27 \%$, and even up to $37 \%$, excluding data from places where adherence was low. It was also noted that efficacy was much greater among women over 21, who also had greater adherence to ring use. Finally, it should be emphasized that there was neither an increase in adverse effects among users nor any development of resistance among the infected women. ${ }^{156}$ Another Phase III study with a ring containing DPV, known as The Ring Study, found it reduced the risk of HIV acquisition by $31 \%$. The results of this study coincide with the ASPIRE trial in claiming that the efficacy is much greater in women over 21, suggesting the influence of the physiology of the vaginal tract, a lower adherence to the use of the ring or the frequency of sexual intercourse as potential factors affecting efficacy. This study also coincides with the ASPIRE trial by ruling out the incidence of adverse effects and the development of resistances. ${ }^{154}$

These findings undoubtedly suggest that intravaginal ring delivery of DPV is a viable option for HIV prevention that merits further study, since as in clinical trials with the TFV gel, adherence was once again highlighted as a key factor in the efficacy of HIV prevention. ${ }^{128,150,152,156,157}$

\section{Development of alternative dosage forms}

While initially gels were the pharmaceutical form of choice for vaginal microbicides, and although in recent years vaginal rings have gained acceptance due to their ability to control release over long periods of time, these are not the only dosage forms that have been investigated for this purpose. This variety is necessary because the efficacy of the same antiretroviral drug varies depending on the formulation selected, and because the development of different pharmaceutical forms ensures that women have a wide range of options to protect themselves from the transmission of the virus, and therefore, each user can select the one that best suits her characteristics. ${ }^{158,159}$

\section{Vaginal tablets}

Tablets have the advantage of being easy and economical to manufacture on an industrial scale, easy to handle and stable under different environmental conditions. ${ }^{7,159}$ If the aim is instant protection after administration, fast-dissolving tablets can be obtained depending on the excipients used in their development. ${ }^{159,160}$ Tablets can also be manufactured to release the drug in a sustained manner, enabling controlled drug release and remaining effective for longer, in turn requiring fewer applications and favoring adherence to treatment. One example of this is the tablets made from polymers capable of gelling in the presence of vaginal fluid (Figure 5).

The first references to vaginal tablets to prevent sexual transmission of HIV were of Praneem polyherbal vaginal tablets. Their active ingredient was purified extract of Azadirachta indica, which had shown some in vitro activity against HIV. ${ }^{161}$ Certain adverse effects such as genital itching or irritation were observed in Phase I clinical trials, but it was concluded that the use of the tablets daily for 14 days was safe and accepted by women. ${ }^{161,162}$ Phase II clinical trials to evaluate their long-term safety concluded that their use for 6 months was equally safe and acceptable. ${ }^{163,164}$ However, failures experienced by other formulations contemporary to these tablets, such as nonoxynol-9 or Carraguard gels, demonstrated the need for further preclinical evaluations to verify their effectiveness, and these tablets ultimately never underwent Phase III trials.

Years later, the idea of developing vaginal tablets for HIV prevention was revisited, with the key candidates 


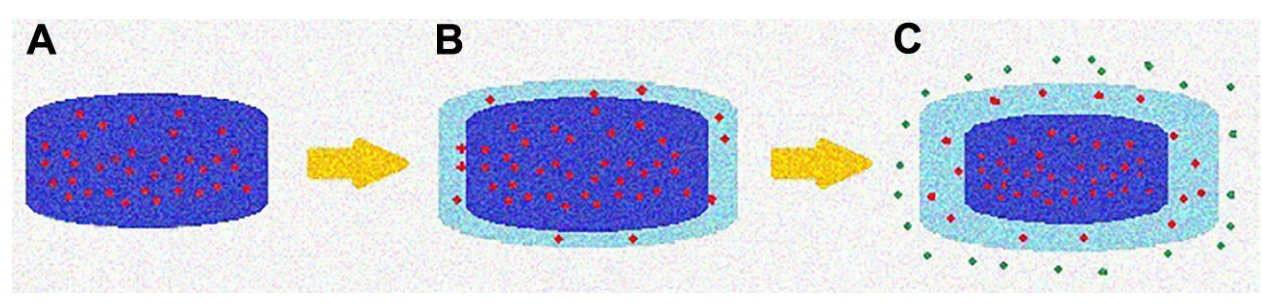

Figure 5 Mechanism of drug release from sustained release tablets by in situ gelation of the polymer.

Notes: At the time of administration, the tablet is completely solid (A). In contact with the vaginal fluid, the polymer of the outer layers forms a drug-loaded gel (B). The drug reaches the vaginal environment by diffusing through the gel layer or by erosion of the gel (C).

being the antiretroviral drugs that had proved most successful in other pharmaceutical forms. TFV vaginal tablets were found, alone or in combination with emtricitabine, another NRTI, to achieve similar concentrations of TFV in the vaginal environment to the $1 \% \mathrm{TFV}$ gel, and proved effective in clinical trials. ${ }^{14,76,165}$ Vaginal tablets ${ }^{166}$ and lyophilized gels ${ }^{167}$ containing DPV, the other drug shown to be effective in clinical trials, have also been developed.

However, these tablets were intended for daily application, or for use in a coitus-dependent manner in the case of immediate-release tablets, so the trend toward pharmaceutical forms capable of releasing the drug for several days led to the abandonment of these tablets.

More recently, we have seen the emergence of some alternatives such as osmotic tablets with IQP-058, which have shown an ability to achieve high levels of the drug in the vaginal mucosa for 10 days (Figure 6). ${ }^{168}$ Lastly, current research is exploring the possibility of manufacturing controlled-release TFV vaginal tablets formulated with mucoadhesive polymers - such as carrageenan, chitosan or cellulose derivatives - that have high binding capacity to the mucosa for significant periods of time. Several studies include these polymers in vaginal formulations to increase their dwelling time at the site of action. If these formulations were to include a suitable mucoadhesive polymer or a polymer mixture, an optimum formulation could be developed for the controlled release of the drug in the area where HIV transmission occurs. ${ }^{76}$

\section{Vaginal films}

Quick-dissolving films are promising and attractive dosage forms that may provide an alternative platform for the vaginal delivery of microbicide drug candidates. These are thin strips of water-soluble polymers that dissolve when they are placed in the vaginal mucosa, releasing the active ingredient. ${ }^{159}$ Vaginal films have advantages such as discreet use, no product leakage during use, not requiring an applicator for insertion and offering rapid drug release with minimal packaging and reduced waste. ${ }^{169}$ Some of the possible disadvantages after administration are local irritation and influence on sexual intercourse. It should also be noted that their large-scale production today would be more complicated than the options described above, not because of the cost of the materials required, but because of the underdevelopment of the production resources. Women's preferences regarding the physicochemical characteristics of these films have been evaluated, and according to one study, they prefer smooth, thin, translucent, square films. ${ }^{170}$

The history of films as microbicides to prevent sexual acquisition of HIV began in a similar way to gels, since the first references found date from the 1990s, with vaginal films containing the spermicide nonoxynol-9. As with the gel, trials in women showed that continued use of nonoxynol-9 did not block HIV transmission and produced lesions in the vaginal tract that may increase the sexual transmission of STIs. ${ }^{171,172}$

Sometime after the failure of nonoxynol-9, films were developed containing other substances with potential activity

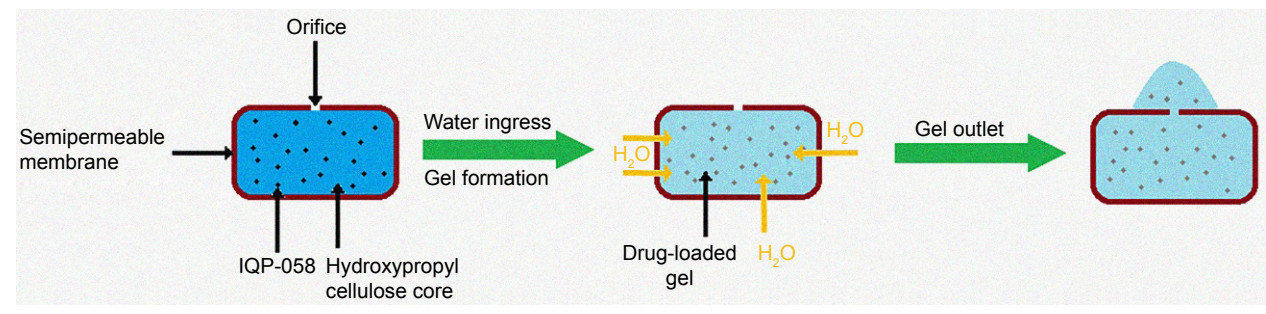

Figure 6 Mechanism of drug release from osmotic release tablets. 
against HIV, such as sodium polystyrene sulfonate ${ }^{173}$ and $\mathrm{RC}-101,{ }^{174}$ although none of them reached clinical trials.

Recent years have seen a growing interest in the development of microbicidal vaginal films, now produced with the incorporation of antiretroviral drugs. Films can be found incorporating NRTIs, such as a hydroxypropyl methylcellulose (HPMC) film containing abacavir, evaluated in vitro and in vivo in rabbits, and which has proven to be nonirritating to the vagina and capable of releasing the drug. ${ }^{175,176} 4^{\prime}$-Ethynyl2-fluoro-2'-deoxyadenosine is another NRTI that has been incorporated into films made with HPMC and polyvinyl alcohol (polyvinylpirrolidone [PVP]), both alone ${ }^{177}$ and combined with 5-chloro-3-phenylsulfonylindole-2-carboxamide. ${ }^{178}$ In vitro studies on these formulations corroborate their potential to inhibit HIV transmission.

Research has also been done on NNRTIs incorporated in vaginal films, of which DPV is unsurprisingly the most studied. These DPV-loaded films have been shown to prevent HIV-1 infection in vitro and ex vivo and have acceptable characteristics. ${ }^{169}$ Recent Phase I clinical trials have demonstrated their safety and ability to release the drug and attain sufficient concentrations in the vaginal tissues to block HIV activity. ${ }^{179}$ Further studies are thus awaited to evaluate the effectiveness of the formulation. ${ }^{180}$

There are also microbicidal films containing other NRTIs, such as a polyvinyl alcohol (PVA) film with the pyrimidinedione IQP-0528 ${ }^{181}$ and an HPMC and polyethylene glycol (PEG) 400 film with the antiretroviral UAM01398. ${ }^{182}$

\section{The future of microbicides Growing interest in nanosystems: nanomicrobicides}

The high versatility of nanoparticles, which have transformed several fields of biomedical science, has led to intense research activity in this area in recent years. ${ }^{183}$ These nanoparticles can be made using both inorganic materials and a wide variety of biodegradable and biocompatible polymers.

Thanks to their small size, they are able to internalize in cells and release the drug directly to the cytosol. ${ }^{184}$ Their large surface area improves the dissolution and absorption of slightly soluble drugs, and also allows optimization of these nanoparticles according to their functionalization; they can bind to specific targets by multivalent conjugations and attach at the drug release site. ${ }^{183-185}$ However, the complexity of the equipment required to obtain particles of this size would increase the cost of the formulation.

These nanosystems can either exhibit HIV inhibitory activity by themselves or serve as a vehicle for drug delivery. ${ }^{183}$
Recent research has focused on the possibility of developing microbicides based on nanoparticles for HIV prevention. These nanoparticles consist of crosslinked polymer chains formed thanks to crosslinking agents, creating a structure within which to load the drug (Figure 7).

Their small size means that some of these particles can interact directly with HIV. In vitro viral adhesion has been observed with silver nanoparticles, and silver-coated PVP nanoparticles have demonstrated antiviral activity ex vivo at nontoxic concentrations. ${ }^{186}$ This adhesion could be applicable to other noble metals such as gold. ${ }^{187}$ The same researchers demonstrated the additive effect of the antiviral activity of silver nanoparticles when used in combination with monoclonal antibodies. ${ }^{188}$

Another option is to load nanoparticles with antiretroviral drugs, of which the most common are again TFV and DPV. For example, solid lipid nanoparticles of polylysineheparin loaded with TFV have been shown to improve the cellular internalization of the microbicide and are not cytotoxic. ${ }^{189}$ In the case of DPV, there are several references for nanoparticles based on polycaprolactone (PCL). ${ }^{190,191}$ Other researches focused on developing nanoparticles of poly(D,L-lactic-co-glycolic acid) (PLGA) loaded with DPV, a formulation that has interesting technological and biologic characteristics for use in safe and effective vaginal microbicides. These nanoparticles are capable of releasing the drug for 24 hours at both $\mathrm{pH} 4.2$ and 7.4, and their cytotoxicity is no higher than that of the free drug. ${ }^{192}$ Another NNRTI evaluated for the prevention of sexual transmission of HIV is rilpivirine. PLGA nanoparticles have been developed with this drug and incorporated in a thermosensitive gel capable of offering significant protection against HIV-1 in mice. ${ }^{106}$ However, most efforts to prevent HIV with rilpivirine do not focus on vaginal administration,

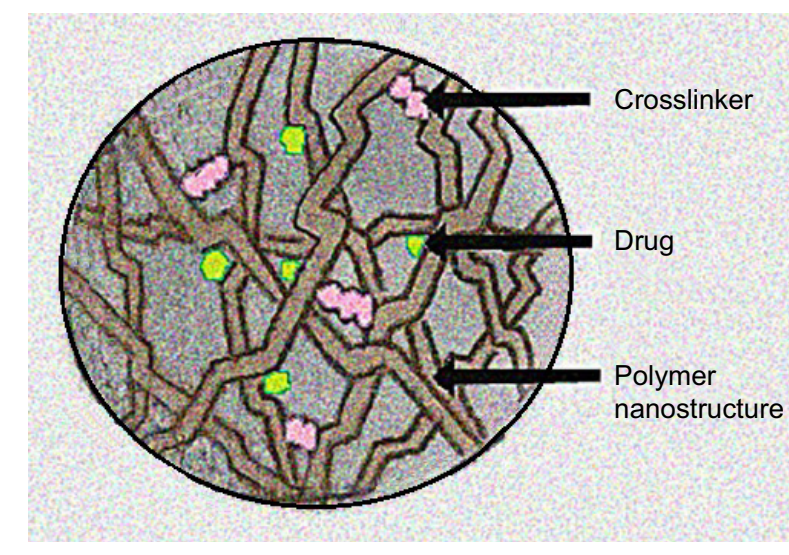

Figure 7 Structure of a drug-loaded polymer nanoparticle. 
but on the intramuscular administration of long-acting rilpivirine. ${ }^{104,105}$

Once a nanogel that can retain the drug during loading and release it in a sustained way has been obtained, it is sometimes necessary to fit another set of parameters to affect the time of permanence of the nanoparticles and their concentration in the place they are required to exert their action. ${ }^{193}$ The mucoadhesion can be changed by modifying the nanoparticle surface, for example, as in the case of chitosan nanoparticles loaded with TFV, which were coated with sodium triphosphate pentabasic to improve their mucoadhesion. ${ }^{194}$ When these particles were made with a mixture of chitosan and thioglycolic acid, the mucoadhesion was even higher. ${ }^{195}$

Other modifications to the surface of the nanoparticles aim to improve their internalization in the vaginal mucosa. For example, PCL nanoparticles loaded with DPV have been developed and coated to assess how the surface charge affects their internalization in a simulated vaginal fluid medium incorporating mucin. The results of this study suggest that negatively charged particles are more suitable for the release of DPV into the vaginal mucosa, as they were able to pass through the medium much faster than positively charged particles. ${ }^{196}$ Their ability to internalize in the cells was evaluated, and was observed to be greater than in the case of uncharged particles; there was also a correlation between the increase in intracellular drug release and antiviral activity. ${ }^{190,191,197}$

Finally, the nanoparticle surface can also be modified to increase its concentration at the site of action. Specific ligands are added to the surface and find their target at the drug's action site, allowing them to be retained and release the drug when they reach the target. ${ }^{193}$ PLGA nanoparticles loaded with the antiretroviral drug saquinavir have been conjugated to the anti-CD4 antibody. The nanoparticles thus bind to the $\mathrm{CD}^{+}$immune cells and the drug is specifically released inside them. ${ }^{198}$

Stimuli-sensitive materials are of significant interest in obtaining nanoparticles, since their physical and chemical nature can be modified in response to external stimuli such as $\mathrm{pH}$ or temperature. Nanoparticles of PLGA and methacrylic acid copolymer (Eudragit ${ }^{\circledR}$ S-100) have been loaded with TFV and are capable of releasing the drug in a $\mathrm{pH}$-dependent manner in the presence of seminal fluid. ${ }^{199}$ Another example of release in response to stimuli is the nanoparticles of hyaluronic acid loaded with TFV, which release the drug in the presence of semen due to the degradation of hyaluronic acid in the presence of the enzyme hyaluronidase. ${ }^{200}$
An alternative option is to include the nanoparticles in a stimuli-sensitive dosage form, such as temperature-sensitive gels that are liquid at room temperature, convenient to apply and gain consistency at body temperature, thus avoiding vaginal seepage after application and maintaining the nanoparticles in contact with the mucosa for longer. Formulations with PLGA nanoparticles loaded with $\mathrm{TFV}^{201}$ or with rilpivirine ${ }^{106}$ have been developed using these gels.

After manufacturing the nanoparticles, they must be properly formulated to develop vaginal microbicides that women can apply easily. The most common dosage form is as a gel, but the inclusion of nanoparticles in polymer films has recently been evaluated. ${ }^{202}$ The advantages of nanoparticles combine with the benefits of the films described above; examples of this are PVA films incorporating nanoparticles loaded with small interfering RNA. ${ }^{203}$ The incorporation of nanoparticles loaded with TFV or efavirenz into a film based on HPMC, PVA and glycerine was also evaluated, ${ }^{204}$ and was found to produce sustained release of the drug for 24 hours and was found to be safe at in vivo trials. ${ }^{205}$ Finally, it is worth mentioning another similar case in which PLGA nanoparticles were loaded with another antiretroviral, IQP-0528, and incorporated into a fast-dissolving film. ${ }^{206}$

For all these reasons, despite the current scarcity of microbicides based on nanosystems for the prevention of HIV, coming years will see a boom in research in this field, since nanoparticles provide a delivery strategy for targeted and controlled delivery of drugs to the vagina. ${ }^{183,185}$

\section{Novel dosage forms: electrospun fibers}

Although research based on more traditional pharmaceutical forms continues to be the main route for the development of vaginal microbicides, other less widely studied alternatives have been gaining importance in recent years and could offer a therapeutic alternative.

A recent new pharmaceutical form consists of drugloaded polymer fibers known as electrospun fibers, which are produced by electrospinning, a technique that applies electrostatic forces to form polymeric fibers (Figure 8). ${ }^{207}$ Polyglycolic acid, polylactic acid, PCL and PLGA are the most common polymers used in their manufacture. ${ }^{208}$

Unlike nanoparticles, which can internalize in the cells and release the drug, the fibers can only control the release of the drug through erosion and degradation of the polymer and diffusion of the incorporated drug. These materials offer an alternative to existing microbicides, as they can quickly in $<15$ minutes - release the active ingredient in wet areas, especially if they contain a wetting agent as a carrier. ${ }^{207,209}$ 


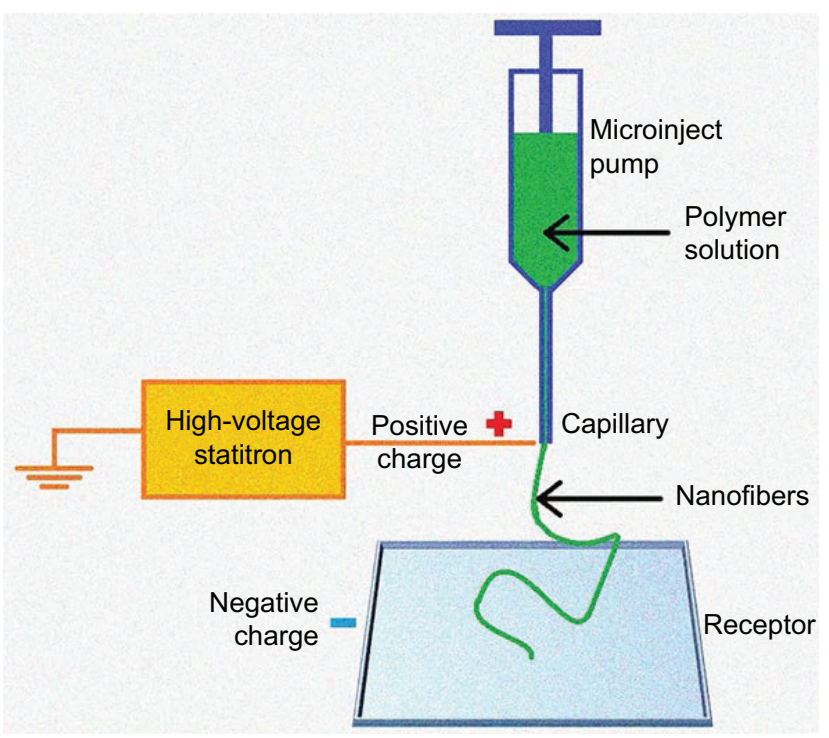

Figure 8 Diagram of the nanofiber manufacturing process by electrospinning.

The development of an effective microbicide in this formulation would be a useful tool for preventing HIV transmission, since its application prior to sexual relations would provide almost immediate protection. However, polymers that take longer to degrade in the vaginal medium can also be used in order to achieve sustained release of the drug, in some cases with over 7 days of sustained release. ${ }^{207}$ As in the case of nanomicrobicides, a significant financial investment is required to purchase the equipment needed to obtain these formulations.

Some examples of vaginal microbicides formulated as electrospun fibers include TFV. PVA nanofibers loaded with this antiretroviral are capable of releasing $95 \%$ of the drug within 5 minutes in in vitro studies at a $\mathrm{pH}$ of both 4.3, equivalent to the $\mathrm{pH}$ of vaginal fluid, and 7.4, equivalent to the $\mathrm{pH}$ of seminal fluid. ${ }^{210,211}$ Stimuli-sensitive, TFV-loaded nanofibers have also been developed based on thiolated hyaluronic acid, which release the drug only in the presence of semen, when the polymer degrades in the presence of the seminal hyaluronidase enzyme. ${ }^{212}$

Other nanofibers have incorporated antiretrovirals with a different mechanism of action, such as MVC, an entry inhibitor. A new study formulated electrospun solid dispersions of MVC with PVP or with poly(ethylene oxide). In the MVC in vitro release assays, $95 \%$ of the dose was released in 14 minutes when it was included in PVP fibers and in 18 minutes with the poly(ethylene oxide) fibers. When these electrospun fibers were manufactured with the addition of Tween 20 as a wetting agent, drug release was accelerated and at least $95 \%$ of the drug was released within 6 minutes. ${ }^{209}$ As a variant of these MVC-loaded PVP fibers, more recently, PVP fibers in coaxially electrospun fibers were coated with ethyl cellulose, achieving sustained release of MVC for up to 120 hours. ${ }^{213}$

Finally, to highlight the rise of this new dosage form, it is worth noting that other antivirals are also being evaluated for this form of delivery, such as the recent development of electrospun nanofibers with griffithsin, which has shown in vitro efficacy against HIV-1 infection. ${ }^{214}$

This formulation could represent a major step forward in the development of vaginal microbicides, since it could improve their adherence regardless of their release rate. Rapidly dissolving electrospun fibers could offer immediate protection against the virus, and their use would be coitus dependent, so their administration would only be required prior to sexual intercourse. Fibers capable of delivering sustained release of the drug over several days would also offer a therapeutic advance in terms of adherence, since although the administration is coitus independent, daily applications would not be required. ${ }^{207}$

\section{Genetically modified microorganisms: microbicidal probiotics}

Although the potential of microbicidal probiotics as microbicides is still controversial, they are rapidly gaining acceptance. They work by promoting vaginal colonization by genetically modified microorganisms that can express molecules capable of inhibiting HIV. This strategy would require a high initial investment to genetically modify the microorganisms, but the possibility of these bacteria colonizing the vaginal medium would provide lasting protection that could offset such a substantial investment.

Currently under study are bacteria from the genera Lactobacillus and Bifidobacterium, common in the human vaginal microbiota, to determine whether these genetically modified microorganisms are stable, adhere and persist in the vaginal mucosa and produce the compound of interest in sufficient and sustained concentrations to inhibit the virus without damaging the normal balance of the vaginal microflora. ${ }^{215,216}$

A strain of Lactobacillus jensenii has been developed that is capable of colonizing mice vaginas and producing high levels of CV-N for long periods of time. ${ }^{217}$ The same bacterial strain was studied in macaques, where it was demonstrated that its use is not only safe, but can also have a positive impact on the vaginal environment. ${ }^{218} \mathrm{~A}$ subsequent 
study showed that macaques colonized with this bacterium had a significant reduction in the transmission of a chimeric simian-HIV strain (SHIV-SF162P3). ${ }^{219}$ The safety and toxicity of this strain have also been evaluated, as these are the most contested aspects when using probiotics as microbicides. In vivo tests on macaques have shown that their use is not only safe, but could also have a beneficial impact on the vaginal environment, with lower levels of inflammation in the macaques retaining this strain. ${ }^{218}$ Another therapeutic alternative explored by the authors of these studies is the modification of this strain to express fragments of antibodies against HIV on its surface. ${ }^{220}$

Although there is still a need for more studies on the subject, this strategy undeniably represents an important step in the development of a lasting and inexpensive microbicide to block sexual transmission of HIV in women.

\section{Broadening the spectrum of microbicides: combining drugs with different mechanisms of action}

Following the successful combination of antiretroviral drugs for the treatment of HIV infection, strategies for microbicide development today involve designing dosage forms that combine drugs with different mechanisms of action which are released simultaneously in order to boost the effectiveness of the protection.

One widely studied combination is TFV, antiretroviral NRTI and DPV, an NNRTI, which have been used to develop polymeric films ${ }^{15,221}$ and intravaginal polyurethane rings. ${ }^{18}$ It was observed in ex vivo studies on the films that the coadministration of the two drugs caused a higher concentration of DPV in the tissue, whereas TFV was not affected. In the case of vaginal rings, both drugs were seen to be released together in vitro for 30 days.

Another well-studied combination is of DPV with the entry inhibitor MVC. Although films have also been developed that combine these two drugs, ${ }^{15}$ this combination has been studied mainly for use in vaginal rings, since its objective is to improve the protection offered by successful DPV rings. After evaluating the combination of DPV with different amounts of MVC, a ring with $25 \mathrm{mg}$ of DPV and $100 \mathrm{mg}$ of MVC was selected for clinical trials. ${ }^{222}$ Phase I trials demonstrated that the rings were safe and well tolerated, ${ }^{223}$ but the plasma concentration of DPV was much higher when the ring contained both drugs than when it included only DPV. However, detectable concentrations of MVC were found only in cervicovaginal fluid, but not in plasma. ${ }^{224}$

Another option is the combination of TFV and MVC, used to develop intravaginal rings, ${ }^{225}$ films ${ }^{15}$ and even more novel formulations such as nanolipogels-nanoparticles whose core is a hydrogel wrapped in a lipid shell. ${ }^{226}$

Although TFV, DPV and MVC are the most commonly used drugs in antiretroviral combinations, alternative combinations of other active substances have also been evaluated, such as PLGA nanoparticles loaded with raltegravir and efavirenz, which are subsequently included in a thermosensitive ethyl cellulose gel. ${ }^{227}$

These studies demonstrate that combinations of antiretrovirals capable of inhibiting HIV transmission have potential as prevention strategies against sexual transmission of the virus.

There are a large number of vaginal microbicide formulations currently under investigation. Table 2 summarizes

Table 2 Vaginal formulations for the prevention of sexual transmission of HIV

\begin{tabular}{|c|c|c|c|c|c|c|}
\hline $\begin{array}{l}\text { Mechanism of } \\
\text { action }\end{array}$ & Microbicide & $\begin{array}{l}\text { Pharmaceutical } \\
\text { form }\end{array}$ & Animal tests & $\begin{array}{l}\text { Clinical } \\
\text { trials }\end{array}$ & Current status & References \\
\hline \multirow[t]{4}{*}{ Surfactants } & Nonoxynol-9 & Gel & - & Not safe & Rejected & 20,24 \\
\hline & & Film & & Not effective & & 171, 172 \\
\hline & Savvy gel ${ }^{\circledast}$ & Gel & - & Safe & Rejected & 21,23 \\
\hline & & & & Not effective & & \\
\hline \multirow[t]{2}{*}{ Acidifier } & BufferGel $^{\circledR}$ & Gel & - & Safe & Rejected & 32,33 \\
\hline & & & & Not effective & & \\
\hline \multirow[t]{6}{*}{ Polyanions } & Carraguard $^{\circledR}$ & Gel & - & Safe & Its use as a carrier & $25-28,30$ \\
\hline & & & & Not effective & is being assessed & \\
\hline & PRO $2000^{\circledR}$ & & Safe & Safe & Rejected & $32,33,35-37$ \\
\hline & & & Effective & Not effective & & \\
\hline & VivaGel $^{\circledR}$ & & Safe & Not safe & Rejected & $38-46$ \\
\hline & & & Effective & & & \\
\hline
\end{tabular}

(Continued) 
Table 2 (Continued)

\begin{tabular}{|c|c|c|c|c|c|c|}
\hline $\begin{array}{l}\text { Mechanism of } \\
\text { action }\end{array}$ & Microbicide & $\begin{array}{l}\text { Pharmaceutical } \\
\text { form }\end{array}$ & Animal tests & $\begin{array}{l}\text { Clinical } \\
\text { trials }\end{array}$ & Current status & References \\
\hline \multirow[t]{3}{*}{$\begin{array}{l}\text { gpl20-neutralizing } \\
\text { monoclonal } \\
\text { antibody }\end{array}$} & Vitamin $B_{12}$ & Gel & $\begin{array}{l}\text { Safe } \\
\text { Dose-dependent } \\
\text { effectiveness }\end{array}$ & - & $\begin{array}{l}\text { Large amounts are required } \\
\text { and it is very expensive to } \\
\text { produce }\end{array}$ & $50-52$ \\
\hline & Cyanovirin-N & Gel & $\begin{array}{l}\text { Safe } \\
\text { Effective }\end{array}$ & - & $\begin{array}{l}\text { Candidate for clinical trials } \\
\text { It has been expressed and } \\
\text { purified from transgenic } \\
\text { plants }\end{array}$ & $55-59$ \\
\hline & & $\begin{array}{l}\text { Probiotics (genetically } \\
\text { modified Lactobacillus } \\
\text { jensenii strain) }\end{array}$ & $\begin{array}{l}\text { Safe and positive } \\
\text { for the vaginal } \\
\text { environment } \\
\text { Effective }\end{array}$ & - & In clinical trials & $217-219$ \\
\hline \multirow[t]{3}{*}{ Entry inhibitors } & Maraviroc & $\begin{array}{l}\text { Gel (hydroxyethyl } \\
\text { cellulose) }\end{array}$ & $\begin{array}{l}\text { Safe } \\
\text { Effective }\end{array}$ & - & $\begin{array}{l}\text { Its period of effectiveness } \\
\text { must be increased }\end{array}$ & $69-7 \mid$ \\
\hline & & Gel (silicone) & $\begin{array}{l}\text { Higher and } \\
\text { sustained } \\
\text { concentrations }\end{array}$ & - & Candidate for clinical trials & 72,73 \\
\hline & & Intravaginal ring & Safe & & $\begin{array}{l}\text { Controlled release over } \\
28 \text { days }\end{array}$ & 140 \\
\hline \multirow[t]{8}{*}{$\begin{array}{l}\text { Viral enzyme } \\
\text { inhibitors }\end{array}$} & $\begin{array}{l}\text { Tenofovir/ } \\
\text { tenofovir } \\
\text { disoproxil }\end{array}$ & Gel & $\begin{array}{l}\text { Safe } \\
\text { Effective }\end{array}$ & $\begin{array}{l}\text { Safe } \\
\text { Effective }\end{array}$ & $\begin{array}{l}\text { The first microbicide that } \\
\text { demonstrated efficacy } \\
\text { in women }\end{array}$ & $80-89,100$ \\
\hline & fumarate & Intravaginal ring & $\begin{array}{l}\text { Safe } \\
\text { Effective }\end{array}$ & Safe & $\begin{array}{l}\text { In clinical trials } \\
\text { It provides lasting } \\
\text { protection in animals }\end{array}$ & $16,17,132-138$ \\
\hline & & $\begin{array}{l}\text { Nanoparticles (into } \\
\text { a film) }\end{array}$ & Safe & - & $\begin{array}{l}\text { Controlled release over } \\
24 \text { hours } \\
\text { Further evaluation is needed }\end{array}$ & 204,205 \\
\hline & MIV-I50 & Gel & Effective & Safe & In clinical trials & $107,109-111,113,116$ \\
\hline & & Intravaginal ring & Effective & - & Candidate for clinical trials & $|4|-\mid 44$ \\
\hline & Dapivirine & Gel & $\begin{array}{l}\text { Safe } \\
\text { Effective }\end{array}$ & Safe & In clinical trials & $119-123$ \\
\hline & & Intravaginal ring & $\begin{array}{l}\text { Safe } \\
\text { Effective }\end{array}$ & $\begin{array}{l}\text { Safe } \\
\text { Effective }\end{array}$ & $\begin{array}{l}\text { Controlled release over } \\
28 \text { days } \\
\text { Has demonstrated efficacy } \\
\text { in women }\end{array}$ & $|5|-156$ \\
\hline & & Film & $\begin{array}{l}\text { Safe } \\
\text { Effective }\end{array}$ & Safe & In clinical trials & 169,179 \\
\hline
\end{tabular}

some of these and shows only those for which references to clinical trials or at least in vivo studies have been found. The different mechanisms of action and the various pharmaceutical forms give a clear picture of the benefits and drawbacks of each microbicide, and highlight the advances in these formulations. The ultimate goal is to achieve a vaginal microbicide that is lasting, safe, highly efficient and economical, in order to ensure protection of women against the acquisition of HIV.

\section{Conclusion}

On the basis of the above, it can be concluded that microbicides are a promising tool for the prevention of sexual transmission of HIV, although there is still a long way to go. The large number of microbicides tested in the last two decades have produced more failures than successes, but it is crucial to learn from the mistakes in ineffective formulations to develop an effective vaginal microbicide.

In the short term, microbicides based on reverse transcriptase inhibitors, such as TFV gel or DPV vaginal rings, are at a more advanced stage of development and have yielded the best results to date. It is imperative to continue the research into the potential of these drugs, so that other pharmaceutical forms can be developed to ensure women have multiple options for protecting themselves against infection with the virus.

In the long term, it is worth assessing other microbicides whose clinical application is currently far down the line, either because they are at an earlier stage of development such as products created by nanotechnology, electrospun 
solid dispersions or genetically modified microorganisms - or owing to the need to overcome certain barriers such as high cost, lack of adherence or difficulty in maintaining sustained concentrations.

\section{Acknowledgment}

This study was funded by the project MAT2012-34552 from the Spanish Ministry of Economy and Competitiveness (MINECO) entitled, "Mucoadhesive formulations for the sustained release of vaginal microbicides for the prevention of sexually transmitted diseases".

\section{Authors' contributions}

RRC and MDVO were responsible for the approach to this work, and all the authors participated in the design. FNP wrote the article, and MDVO and RRC conducted a critical review with important intellectual contributions. All three authors have approved the final version for publication.

MDVO, on behalf of the other signatories, guarantees the accuracy, transparency and truthfulness of the data and information contained in the study, and also that no relevant information has been omitted, and that all discrepancies between authors have been adequately resolved and described.

\section{Disclosure}

The authors report no conflicts of interest in this work.

\section{References}

1. World Health Organization [webpage on the Internet]. HIV/AIDS. Available from: http://www.who.int/topics/hiv_aids/en/. Accessed December 15, 2016.

2. National Institute of Allergy and Infectious Diseases [webpage on the Internet]. The relationship between the human immunodeficiency virus and the acquired immunodeficiency syndrome. Available from: http:// www.niaid.nih.gov/topics/hivaids/understanding/howhivcausesaids/ pages/relationshiphivaids.aspx. Accessed December 20, 2016.

3. World Health Organization [webpage on the Internet]. Global HIV prevalence has levelled off. Available from: http://www.who.int/ mediacentre/news/releases/2007/pr61/en/. Accessed December 4, 2016.

4. UNAIDS [webpage on the Internet]. AIDS by the numbers; 2015 . Available from: http://www.unaids.org/sites/default/files/media_asset/ AIDS_by_the_numbers_2015_en.pdf. Accessed December 20, 2016.

5. UNAIDS [webpage on the Internet]. Global report: UNAIDS report on the global AIDS epidemic; 2013. Available from: http://www.unaids.org/ sites/default/files/media_asset/UNAIDS_Global_Report_2013_en_1. pdf. Accessed December 15, 2016.

6. UNAIDS [webpage on the Internet]. The gap report. Available from: http://www.unaids.org/sites/default/files/media_asset/UNAIDS_Gap_ report_en.pdf. Accessed December 15, 2016.

7. Sánchez-Sánchez MP, Martín-Illana A, Ruiz-Caro R, et al. Chitosan and Kappa-Carrageenan vaginal acyclovir formulations for prevention of genital herpes. In vitro and ex vivo evaluation. Mar Drugs. 2015;13(9): 5976-5992.

8. Garg S, Tambwekar KR, Vermani K, et al. Development pharmaceutics of microbicide formulations. Part II: formulation, evaluation, and challenges. AIDS Patient Care STDS. 2003;17(8):377-399.
9. Laeyendecker O, Redd AD, Nason M, et al. Antibody maturation in women who acquire HIV infection while using antiretroviral preexposure prophylaxis. $J$ Infect Dis. 2015;212(5):754-759.

10. Marrazzo JM, Ramjee G, Richardson BA, et al. Tenofovir-based preexposure prophylaxis for HIV infection among African women. N Engl J Med. 2015;372(6):509-518.

11. Hladik F, Burgener A, Ballweber L, et al. Mucosal effects of tenofovir 1\% gel. Elife. 2015;4:e04525.

12. Burns RN, Hendrix CW, Chaturvedula A. Population pharmacokinetics of tenofovir and tenofovir-diphosphate in healthy women. J Clin Pharmacol. 2015;55(6):629-638.

13. Yang KH, Hendrix C, Bumpus N, et al. A multi-compartment single and multiple dose pharmacokinetic comparison of rectally applied tenofovir $1 \%$ gel and oral tenofovir disoproxil fumarate. PLoS One. 2014; 9(10):e106196.

14. Clark MR, Peet MM, Davis S, Doncel GF, Friend DR. Evaluation of rapidly disintegrating vaginal tablets of tenofovir, emtricitabine and their combination for HIV-1 prevention. Pharmaceutics. 2014;6(4):616-631.

15. Akil A, Agashe H, Dezzutti CS, et al. Formulation and characterization of polymeric films containing combinations of antiretrovirals (ARVs) for HIV prevention. Pharm Res. 2015;32(2):458-468.

16. Srinivasan P, Dinh C, Zhang J, et al. Pharmacokinetic evaluation of tenofovir disoproxil fumarate released from an intravaginal ring in pigtailed macaques after 6 months of continuous use. J Med Primatol. 2014;43(5):364-369.

17. Smith JM, Srinivasan P, Teller RS, et al. Tenofovir disoproxil fumarate intravaginal ring protects high-dose depot medroxyprogesterone acetate-treated macaques from multiple SHIV exposures. $J$ Acquir Immune Defic Syndr. 2015;68(1):1-5.

18. Johnson TJ, Gupta KM, Fabian J, Albright TH, Kiser PF. Segmented polyurethane intravaginal rings for the sustained combined delivery of antiretroviral agents dapivirine and tenofovir. Eur J Pharm Sci. 2010;39(4):203-212.

19. Abdulai MA, Baiden F, Adjei G, et al. An assessment of the likely acceptability of vaginal microbicides for HIV prevention among women in rural Ghana. BMC Womens Health. 2012;12(1):40-47.

20. Wilkinson D, Tholandi M, Ramjee G, Rutherford GW. Nonoxynol-9 spermicide for prevention of vaginally adquired HIV and other sexually transmitted infections: systematic review and meta-analysis of randomised controlled trials including more than 5,000 women. Lancet Infect Dis. 2002;2(10):613-617.

21. Feldblum PJ, Adeiga A, Bakare R, et al. SAVVY vaginal gel (C31G) for prevention of HIV infection: a randomized controlled trial in Nigeria. PLoS One. 2008;3(1):e1474.

22. Obiero J, Mwethera PG, Wiysonge CS. Topical microbicides for prevention of sexually transmitted infections. Cochrane Database Syst Rev. 2012;(6):CD007961.

23. Peterson L, Nanda K, Opoku BK, et al. SAVVY (C31G) gel for prevention of HIV infection in women: a Phase 3, double-blind, randomized, placebo-controlled trial in Ghana. PLoS One. 2007;2(12): e1312.

24. Smith-McCune K, Chen JC, Greenblatt RM, et al. Unexpected inflammatory effects of intravaginal gels (Universal Placebo Gel and Nonoxynol-9) on the upper female reproductive tract: a randomized crossover study. PLoS One. 2015;10(7):e0129769.

25. Skoler-Karpoff S, Ramjee G, Ahmed K, et al. Efficacy of Carraguard for prevention of HIV infection in women in South Africa: a randomised, double-blind, placebo-controlled trial. Lancet. 2008; 372(9654):1977-1987.

26. Carraguard Phase II South Africa Study Team. Expanded safety and acceptability of the candidate vaginal microbicide Carraguard ${ }^{\circledR}$ in South Africa. Contraception. 2010;82(6):563-571.

27. McLean CA, van de Wijgert JH, Jones HE, et al. HIV genital shedding and safety of Carraguard use by HIV-infected women: a crossover trial in Thailand. AIDS. 2010;24(5):717-722.

28. Marais D, Gawarecki D, Allan B, et al. The effectiveness of Carraguard, a vaginal microbicide, in protecting women against high-risk human papillomavirus infection. Antivir Ther. 2011;16(8):1219-1226. 
29. Obiero J, Mwethera PG, Hussey GD, Wiysonge CS. Vaginal microbicides for reducing the risk of sexual acquisition of HIV infection in women: systematic review and meta-analysis. BMC Infect Dis. 2012; 12:289.

30. Friedland BA, Stoner M, Chau MM, et al. Baseline predictors of high adherence to a coitally dependent microbicide gel based on an objective marker of use: findings from the Carraguard Phase 3 trial. AIDS Behav. 2016;20(11):2565-2577.

31. Olmsted SS, Khanna KV, Ng EM, et al. Low pH immobilizes and kills human leukocytes and prevents transmission of cell-associated HIV in a mouse model. BMC Infect Dis. 2005;5:79.

32. Tabet SR, Callahan MM, Mauck CK, et al. Safety and acceptability of penile application of 2 candidate topical microbicides: BufferGel and PRO 2000 Gel: 3 randomized trials in healthy low-risk men and HIV-positive men. J Acquir Immune Defic Syndr. 2003;33(4): 476-483.

33. Abdool Karim SS, Richardson BA, Ramjee G, et al. Safety and effectiveness of bufferGel and 0.5\% PRO2000 gel for the prevention of HIV infection in women. AIDS. 2011;25(7):957-966.

34. Morris GC, Lacey CJ. Microbicides and HIV prevention: lessons from the past, looking to the future. Curr Opin Infect Dis. 2010;23(1): $57-63$.

35. Huskens D, Vermeire K, Profy AT, Schols D. The candidate sulfonated microbicide, PRO 2000, has potential multiple mechanisms of action against HIV-1. Antiviral Res. 2009;84(1):38-47.

36. Kamali A, Byomire $\mathrm{H}$, Muwonge $\mathrm{C}$, et al. A randomised placebocontrolled safety and acceptability trial of PRO 2000 vaginal microbicide gel in sexually active women in Uganda. Sex Transm Infect. 2010;86(3):222-226.

37. McCormack S, Ramjee G, Kamali A, et al. PRO2000 vaginal gel for prevention of HIV-1 infection (Microbicides Development Programme 301): a phase 3, randomised, double-blind, parallel-group trial. Lancet. 2010;376(9749):1329-1337.

38. Rupp R, Rosenthal SL, Stanberry LR. VivaGel (SPL7013 Gel): a candidate dendrimer - microbicide for the prevention of HIV and HSV infection. Int J Nanomedicine. 2007;2(4):561-566.

39. Telwatte S, Moore K, Johnson A, et al. Virucidal activity of the dendrimer microbicide SPL7013 against HIV-1. Antiviral Res. 2011; 90(3): 195-199.

40. Price CF, Tyssen D, Sonza S, et al. SPL7013 Gel (VivaGel ${ }^{\circledR}$ ) retains potent HIV-1 and HSV-2 inhibitory activity following vaginal administration in humans. PLoS One. 2011;6(9):e24095.

41. Jiang YH, Emau P, Cairns JS, et al. SPL7013 gel as a topical microbicide for prevention of vaginal transmission of SHIV89.6P in macaques. AIDS Res Hum Retroviruses. 2005;21(3):207-213.

42. Patton DL, Cosgrove Sweeney YT, McCarthy TD, Hillier SL. Preclinical safety and efficacy assessments of dendrimer-based (SPL7013) microbicide gel formulations in a nonhuman primate model. Antimicrob Agents Chemother. 2006;50(5):1696-1700.

43. Chen MY, Millwood IY, Wand H, et al. A randomized controlled trial of the safety of candidate microbicide SPL7013 gel when applied to the penis. J Acquir Immune Defic Syndr. 2009;50(4):375-380.

44. O'Loughlin J, Millwood IY, McDonald HM, Price CF, Kaldor JM, Paull JR. Safety, tolerability, and pharmacokinetics of SPL7013 gel (VivaGel): a dose ranging, phase I study. Sex Transm Dis. 2010;37(2): $100-104$.

45. Moscicki AB, Kaul R, Ma Y, et al. Measurement of mucosal biomarkers in a phase 1 trial of intravaginal 3\% StarPharma LTD 7013 gel (VivaGel) to assess expanded safety. J Acquir Immune Defic Syndr. 2012; 59(2):134-140.

46. McGowan I, Gomez K, Bruder K, et al. Phase 1 randomized trial of the vaginal safety and acceptability of SPL7013 gel (VivaGel) in sexually active young women (MTN-004). AIDS. 2011;25(8):1057-1064.

47. Tan S, Lu L, Li L, et al. Polyanionic candidate microbicides accelerate the formation of semen-derived amyloid fibrils to enhance HIV-1 infection. PLoS One. 2013;8(3):e59777.
48. Zirafi O, Kim KA, Roan NR, et al. Semen enhances HIV infectivity and impairs the antiviral efficacy of microbicides. Sci Transl Med. 2014; 6(262):262ra157.

49. Sonza S, Johnson A, Tyssen D, et al. Enhancement of human immunodeficiency virus type 1 replication is not intrinsic to all polyanion-based microbicides. Antimicrob Agents Chemother. 2009;53(8):3565-3568.

50. Veazey RS, Shattock RJ, Pope M, et al. Prevention of virus transmission to macaque monkeys by a vaginally applied monoclonal antibody to HIV-1 gp120. Nat Med. 2003;9(3):343-346.

51. Sexton A, Harman S, Shattock RJ, Ma JK. Design, expression, and characterization of a multivalent, combination HIV microbicide. FASEB J. 2009;23(10):3590-3600.

52. Pace $\mathrm{C}$, Markowitz M. Monoclonal antibodies to host cellular receptors for the treatment and prevention of HIV-1 infection. Curr Opin HIV AIDS. 2015;10(3):144-150.

53. Li L, Sun T, Yang K, Zhang P, Jia WQ. Monoclonal CCR5 antibody for treatment of people with HIV infection. Cochrane Database Syst Rev. 2010;7(12):CD008439.

54. Akkouh O, Ng TB, Singh SS, et al. Lectins with anti-HIV activity: a review. Molecules. 2015;20(1):648-668.

55. Tsai CC, Emau P, Jiang Y, et al. Cyanovirin-N inhibits AIDS virus infections in vaginal transmission models. AIDS Res Hum Retroviruses. 2004;20(1):11-18.

56. Tsai CC, Emau P, Jiang Y, et al. Cyanovirin-N gel as a topical microbicide prevents rectal transmission of SHIV89.6P in macaques. AIDS Res Hum Retroviruses. 2003;19(7):535-541.

57. Vamvaka E, Evans A, Ramessar K, et al. Cyanovirin-N produced in rice endosperm offers effective pre-exposure prophylaxis against HIV-1BaL infection in vitro. Plant Cell Rep. 2016;35(6):1309-1319.

58. Madeira LM, Szeto TH, Ma JK, Drake PM. Rhizosecretion improves the production of Cyanovirin-N in Nicotiana tabacum through simplified downstream processing. Biotechnol J. 2016;11(7):910-919.

59. O'Keefe BR, Murad AM, Vianna GR, et al. Engineering soya bean seeds as a scalable platform to produce cyanovirin-N, a non-ARV microbicide against HIV. Plant Biotechnol J. 2015;13(7):884-892.

60. O'Keefe BR, Vojdani F, Buffa V, et al. Scaleable manufacture of HIV-1 entry inhibitor griffithsin and validation of its safety and efficacy as a topical microbicide component. Proc Natl Acad Sci U S A. 2009; 106(15):6099-6104.

61. Lusvarghi S, Bewley CA. Griffithsin: an antiviral lectin with outstanding therapeutic potential. Viruses. 2016;8(10):296.

62. Vamvaka E, Arcalis E, Ramessar K, et al. Rice endosperm is costeffective for the production of recombinant griffithsin with potent activity against HIV. Plant Biotechnol J. 2016;14(6):1427-2437.

63. Fuqua JL, Hamorsky K, Khalsa G, Matoba N, Palmer KE. Bulk production of the antiviral lectin griffithsin. Plant Biotechnol J. 2015;13(8): 1160-1168.

64. Fuqua JL, Wanga V, Palmer KE. Improving the large scale purification of the HIV microbicide, griffithsin. BMC Biotechnol. 2015;15:12.

65. Mertenskoetter T, Kaptur PE. Update on microbicide research and development - seeking new HIV prevention tools for women. Eur J Med Res. 2011;16(1):1-6.

66. European Medicines Agency (EMA) [webpage on the internet]. Celsentri $^{\circledR}$. Available from: http://www.ema.europa.eu/docs/en_GB/ document_library/EPAR_-_Summary_for_the_public/human/000811/ WC500022191.pdf. Accessed December 7, 2016.

67. Council OD, Swanson MD, Spagnuolo RA, Wahl A, Garcia JV. Role of semen on vaginal HIV-1 transmission and maraviroc protection. Antimicrob Agents Chemother. 2015;59(12):7847-7851.

68. Dumond JB, Patterson KB, Pecha AL, et al. Maraviroc concentrates in the cervicovaginal fluid and vaginal tissue of HIV-negative women. J Acquir Immune Defic Syndr. 2009;51(5):546-553.

69. Neff CP, Kurisu T, Ndolo T, Fox K, Akkina R. A topical microbicide gel formulation of CCR5 antagonist maraviroc prevents HIV-1 vaginal transmission in humanized RAG-hu mice. PLoS One. 2011; 6(6):e20209. 
70. Malcolm RK, Forbes CJ, Geer L, et al. Pharmacokinetics and efficacy of a vaginally administered maraviroc gel in rhesus macaques. $J$ Antimicrob Chemother. 2013;68(3):678-683.

71. Veazey RS, Ketas TJ, Dufour J, et al. Protection of rhesus macaques from vaginal infection by vaginally delivered maraviroc, an inhibitor of HIV-1 entry via the CCR5 co-receptor. J Infect Dis. 2010;202(5):739-744.

72. Forbes CJ, McCoy CF, Murphy DJ, et al. Modified silicone elastomer vaginal gels for sustained release of antiretroviral HIV microbicides. J Pharm Sci. 2014;103(5):1422-1432.

73. Forbes CJ, Lowry D, Geer L, et al. Non-aqueous silicone elastomer gels as a vaginal microbicide delivery system for the HIV-1 entry inhibitor maraviroc. J Control Release. 2011;156(2):161-169.

74. D'Cruz OJ, Uckun FM. Clinical development of microbicides for the prevention of HIV infection. Curr Pharm Des. 2004;10(3):315-336.

75. Adams JL, Kashuba AD. Formulation, pharmacokinetics and pharmacodynamics of topical microbicides. Best Pract Res Clin Obstet Gynaecol. 2012;26(4):451-462.

76. McConville C, Friend DR, Clark MR, Malcolm K. Preformulation and development of a once-daily sustained-release tenofovir vaginal tablet containing a single excipient. J Pharm Sci. 2013;102(6):1859-1868.

77. European Medicines Agency (EMA) [webpage on the Internet]. Viread $^{\mathbb{R}}$. Available from: http://www.ema.europa.eu/docs/en_GB/ document_library/EPAR_-_Product_Information/human/000419/ WC500051737.pdf. Accessed December 12, 2016.

78. Rohan LC, Moncla BJ, Kunjara Na Ayudhya RP, et al. In vitro and ex vivo testing of tenofovir shows it is effective as an HIV-1 microbicide. PLoS One. 2010;5(2):e9310.

79. Nuttall J, Kashuba A, Wang R, et al. Pharmacokinetics of tenofovir following intravaginal and intrarectal administration of tenofovir gel to rhesus macaques. Antimicrob Agents Chemother. 2012;56(1): 103-109.

80. Dobard C, Sharma S, Martin A, et al. Durable protection from vaginal simian-human immunodeficiency virus infection in macaques by tenofovir gel and its relationship to drug levels in tissue. $J$ Virol. 2012;86(2):718-725

81. Mayer KH, Maslankowski LA, Gai F, et al. Safety and tolerability of tenofovir vaginal gel in abstinent and sexually active HIV-infected and uninfected women. AIDS. 2006;20(4):543-551.

82. Schwartz JL, Rountree W, Kashuba AD, et al. A multi-compartment, single and multiple dose pharmacokinetic study of the vaginal candidate microbicide 1\% tenofovir gel. PLoS One. 2011;6(10):e25974.

83. Sokal DC, Karim QA, Sibeko S, et al. Safety of tenofovir gel, a vaginal microbicide, in South African women: results of the CAPRISA 004 trial. Antivir Ther. 2013;18(3):301-310.

84. Keller MJ, Madan RP, Torres NM, et al. A randomized trial to assess anti-HIV activity in female genital tract secretions and soluble mucosal immunity following application of $1 \%$ tenofovir gel. PLoS One. 2011; 6(1):e16475.

85. Rosen RK, Morrow KM, Carballo-Diéguez A, et al. Acceptability of tenofovir gel as a vaginal microbicide among women in a phase I trial: a mixed-methods study. J Womens Health (Larchmt). 2008;17(3): 383-392.

86. Mehendale S, Deshpande S, Kohli R, Tsui S, Tolley E. Acceptability of coitally-associated versus daily use of $1 \%$ tenofovir vaginal gel among women in Pune, India. Int Health. 2012;4(1):63-69.

87. Abdool Karim Q, Abdool Karim SS, Frohlich JA, et al. Effectiveness and safety of tenofovir gel, an antiretroviral microbicide, for the prevention of HIV infection in women. Science. 2010;329(5996): 1168-1174.

88. McConville C, Boyd P, Major I. Efficacy of tenofovir 1\% vaginal gel in reducing the risk of HIV-1 and HSV-2 infection. Clin Med Insights Womens Health. 2014;7:1-8.

89. Hendrix CW, Chen BA, Guddera V, et al. MTN-001: randomized pharmacokinetic cross-over study comparing tenofovir vaginal gel and oral tablets in vaginal tissue and other compartments. PLoS One. 2013;8(1):e55013.
90. Minnis AM, van der Straten A, Salee P, Hendrix CW. Pre-exposure prophylaxis adherence measured by plasma drug level in MTN-001: comparison between vaginal gel and oral tablets in two geographic regions. AIDS Behav. 2016;20(7):1541-1548.

91. Celum C, Baeten JM. Tenofovir-based pre-exposure prophylaxis for HIV prevention: evolving evidence. Curr Opin Infect Dis. 2012;25(1): 51-57.

92. Ariën KK, Vanham G. First real success for anti-HIV gel: a new start for HIV microbicides? Future Microbiol. 2010;5(11):1621-1623.

93. Quiñones-Mateu ME, Vanham G. HIV microbicides: where are we now? Curr HIV Res. 2012;10(1):1-2.

94. Williams BG, Abdool Karim SS, Karim QA, Gouws E. Epidemiological impact of tenofovir gel on the HIV epidemic in South Africa. $J$ Acquir Immune Defic Syndr. 2011;58(2):207-210.

95. Terris-Prestholt F, Foss AM, Cox AP, et al. Cost-effectiveness of tenofovir gel in urban South Africa: model projections of HIV impact and threshold product prices. BMC Infect Dis. 2014;14:14.

96. Gengiah TN, Baxter C, Mansoor LE, Kharsany AB, Abdool Karim SS. A drug evaluation of $1 \%$ tenofovir gel and tenofovir disoproxil fumarate tablets for the prevention of HIV infection. Expert Opin Investig Drugs. 2012;21(5):695-715.

97. van der Straten A, Van Damme L, Haberer JE, Bangsberg DR. Unraveling the divergent results of pre-exposure prophylaxis trials for HIV prevention. AIDS. 2012;26(7):F13-F19.

98. Minnis AM, Gandham S, Richardson BA, et al. Adherence and acceptability in MTN 001: a randomized cross-over trial of daily oral and topical tenofovir for HIV prevention in women. AIDS Behav. 2013; 17(2):737-747.

99. MacQueen KM, Weaver MA, van Loggerenberg F, et al. Assessing adherence in the CAPRISA 004 tenofovir gel HIV prevention trial: results of a nested case-control study. AIDS Behav. 2014;18(5):826-832.

100. Kashuba AD, Gengiah TN, Werner L, et al. Genital tenofovir concentrations correlate with protection against HIV infection in the CAPRISA 004 trial: importance of adherence for microbicide effectiveness. J Acquir Immune Defic Syndr. 2015;69(3):264-269.

101. Herold BC, Chen BA, Salata RA, et al. Impact of Sex on the Pharmacokinetics and Pharmacodynamics of $1 \%$ Tenofovir Gel. Clin Infect Dis. 2016;62(3):375-382.

102. Naranbhai V, Abdool Karim SS, Altfeld M, et al. Innate immune activation enhances hiv acquisition in women, diminishing the effectiveness of tenofovir microbicide gel. J Infect Dis. 2012;206(7):993-1001.

103. D'Cruz OJ, Uckun FM. Dawn of non-nucleoside inhibitor-based antiHIV microbicides. J Antimicrob Chemother. 2006;57(3):411-423.

104. McGowan I, Dezzutti CS, Siegel A, et al. Long-acting rilpivirine as potential pre-exposure prophylaxis for HIV-1 prevention (the MWRI-01 study): an open-label, phase 1, compartmental, pharmacokinetic and pharmacodynamic assessment. Lancet HIV. 2016;3(12):e569-e578.

105. Jackson A, McGowan I. Long-acting rilpivirine for HIV prevention. Curr Opin HIV AIDS. 2015;10(4):253-257.

106. Kovarova M, Council OD, Date AA, et al. Nanoformulations of rilpivirine for topical pericoital and systemic coitus-independent administration efficiently prevent HIV transmission. PLoS Pathog. 2015; 11(8):e1005075.

107. Fernández-Romero JA, Thorn M, Turville SG, et al. Carrageenan/ MIV-150 (PC-815), a combination microbicide. Sex Transm Dis. 2007;34(1):9-14.

108. Turville SG, Aravantinou M, Miller T, et al. Efficacy of Carraguardbased microbicides in vivo despite variable in vitro activity. PLoS One. 2008;3(9):e3162.

109. Kenney J, Aravantinou M, Singer R, et al. An antiretroviral/zinc combination gel provides 24 hours of complete protection against vaginal SHIV infection in macaques. PLoS One. 2011;6(1):e15835.

110. Barnable P, Calenda G, Ouattara L, et al. A MIV-150/zinc acetate gel inhibits SHIV-RT infection in macaque vaginal explants. PLoS One. 2014;9(9):e108109. 
111. Kenney J, Singer R, Derby N, et al. A single dose of a MIV-150/ Zinc acetate gel provides $24 \mathrm{~h}$ of protection against vaginal simian human immunodeficiency virus reverse transcriptase infection, with more limited protection rectally $8-24 \mathrm{~h}$ after gel use. AIDS Res Hum Retroviruses. 2012;28(11):1476-1484.

112. Kizima L, Rodríguez A, Kenney J, et al. A potent combination microbicide that targets SHIV-RT, HSV-2 and HPV. PLoS One. 2014; 9(4):e94547.

113. Barnable P, Calenda G, Bonnaire T, et al. MIV-150/zinc acetate gel inhibits cell-associated simian-human immunodeficiency virus reverse transcriptase infection in a macaque vaginal explant model. Antimicrob Agents Chemother. 2015;59(7):3829-3837.

114. Calenda G, Villegas G, Barnable P, et al. MZC gel inhibits SHIV-RT and HSV-2 in macaque vaginal mucosa and SHIV-RT in rectal mucosa. J Acquir Immune Defic Syndr. 2017;(3):e67-e74.

115. Jean-Pierre N, Barnable P, Kizima L, et al. Multipurpose prevention approaches with antiretroviral-based formulations. Antimicrob Agents Chemother. 2015;60(2):1141-1144.

116. Friedland BA, Hoesley CJ, Plagianos M, et al. First-in-human trial of MIV-150 and zinc acetate co-formulated in a carrageenan gel: safety, pharmacokinetics, acceptability, adherence and pharmacodynamics. J Acquir Immune Defic Syndr. 2016;73(5):489-496.

117. Fletcher P, Harman S, Azijn H, et al. Inhibition of human immunodeficiency virus type 1 infection by the candidate microbicide dapivirine, a nonnucleoside reverse transcriptase inhibitor. Antimicrob Agents Chemother. 2009;53(2):487-495.

118. Dhondt MM, Adriaens E, Roey JV, Remon JP. The evaluation of the local tolerance of vaginal formulations containing dapivirine using the Slug Mucosal Irritation test and the rabbit vaginal irritation test. Eur J Pharm Biopharm. 2005;60(3):419-425.

119. Nuttall JP, Thake DC, Lewis MG, Ferkany JW, Romano JW, Mitchnick MA. Concentrations of dapivirine in the rhesus macaque and rabbit following once daily intravaginal administration of a gel formulation of [14C]dapivirine for 7 days. Antimicrob Agents Chemother. 2008;52(3):909-914.

120. Nel AM, Coplan P, van de Wijgert JH, et al. Safety, tolerability, and systemic absorption of dapivirine vaginal microbicide gel in healthy, HIV-negative women. AIDS. 2009;23(12):1531-1538.

121. Nel AM, Smythe SC, Habibi S, Kaptur PE, Romano JW. Pharmacokinetics of 2 dapivirine vaginal microbicide gels and their safety vs. Hydroxyethyl cellulose-based universal placebo gel. J Acquir Immune Defic Syndr. 2010;55(2):161-169.

122. Nel AM, Coplan P, Smythe SC, et al. Pharmacokinetic assessment of dapivirine vaginal microbicide gel in healthy, HIV-negative women. AIDS Res Hum Retroviruses. 2010;26(11):1181-1190.

123. Cranston RD, Hoesley C, Carballo-Diéguez A, et al. A randomized male tolerance study of dapivirine gel following multiple topical penile exposures (MTN 012/IPM 010). AIDS Res Hum Retroviruses. 2014;30(2):184-189.

124. Sluis-Cremer N. The emerging profile of cross-resistance among the nonnucleoside HIV-1 reverse transcriptase inhibitors. Viruses. 2014; 6(8):2960-2973.

125. Lusti-Narasimhan M, Khosla R, Baggaley R, Temmerman M, McGrory E, Farley T. WHO guidance grounded in a comprehensive approach to sexual and reproductive health and human rights: topical pre-exposure prophylaxis. J Int AIDS Soc. 2014;17(3 Suppl 2):19279.

126. UNAIDS [webpage on the Internet]. Biomedical AIDS Research: Recent and Upcoming Advances. Available from: http:/www.unaids. org/sites/default/files/media_asset/JC2723_Biomedical_AIDS_ research_en.pdf. Accessed December 21, 2016.

127. Hankins CA, Dybul MR. The promise of pre-exposure prophylaxis with antiretroviral drugs to prevent HIV transmission: a review. Curr Opin HIV AIDS. 2013;8(1):50-58

128. Fetherston SM, Malcolm RK, Woolfson AD. Controlled-release vaginal ring drug-delivery systems: a key strategy for the development of effective HIV microbicides. Ther Deliv. 2010;1(6):785-802.
129. Montgomery ET, van der Straten A, Cheng H, et al. Vaginal ring adherence in sub-Saharan Africa: expulsion, removal, and perfect use. AIDS Behav. 2012;16(7):1787-1798.

130. Malcolm RK, Edwards KL, Kiser P, Romano J, Smith TJ. Advances in microbicide vaginal rings. Antiviral Res. 2010;88 (Suppl 1): S30-S39.

131. Thurman AR, Clark MR, Hurlburt JA, Doncel GF. Intravaginal rings as delivery systems for microbicides and multipurpose prevention technologies. Int J Womens Health. 2013;5:695-708.

132. Johnson TJ, Clark MR, Albright TH, et al. A 90-day tenofovir reservoir intravaginal ring for mucosal HIV prophylaxis. Antimicrob Agents Chemother. 2012;56(12):6272-6283.

133. Baum MM, Butkyavichene I, Gilman J, et al. An intravaginal ring for the simultaneous delivery of multiple drugs. J Pharm Sci. 2012; 101(8):2833-2843.

134. Clark JT, Johnson TJ, Clark MR, et al. Quantitative evaluation of a hydrophilic matrix intravaginal ring for the sustained delivery of tenofovir. J Control Release. 2012;163(2):240-248.

135. Moss JA, Malone AM, Smith TJ, et al. Safety and pharmacokinetics of intravaginal rings delivering tenofovir in pig-tailed macaques. Antimicrob Agents Chemother. 2012;56(11):5952-5960.

136. Mesquita PM, Rastogi R, Segarra TJ, et al. Intravaginal ring delivery of tenofovir disoproxil fumarate for prevention of HIV and herpes simplex virus infection. J Antimicrob Chemother. 2012;67(7):1730-1738.

137. Smith JM, Rastogi R, Teller RS, et al. Intravaginal ring eluting tenofovir disoproxil fumarate completely protects macaques from multiple vaginal simian-HIV challenges. Proc Natl Acad Sci US A. 2013;110(40): 16145-16150

138. Keller MJ, Mesquita PM, Marzinke MA, et al. A phase 1 randomized placebo-controlled safety and pharmacokinetic trial of a tenofovir disoproxil fumarate vaginal ring. AIDS. 2016;30(5):743-751.

139. Clark JT, Clark MR, Shelke NB, et al. Engineering a segmented dual-reservoir polyurethane intravaginal ring for simultaneous prevention of HIV transmission and unwanted pregnancy. PLoS One. 2014;9(3):e88509.

140. Malcolm RK, Veazey RS, Geer L, et al. Sustained release of the CCR5 inhibitors CMPD167 and maraviroc from vaginal rings in rhesus macaques. Antimicrob Agents Chemother. 2012;56(5):2251-2258.

141. Singer R, Mawson $P$, Derby N, et al. An intravaginal ring that releases the NNRTI MIV-150 reduces SHIV transmission in macaques. Sci Transl Med. 2012;4(150):150ra123.

142. Hsu M, Keele BF, Aravantinou M, et al. Exposure to MIV-150 from a high-dose intravaginal ring results in limited emergence of drug resistance mutations in SHIV-RT infected rhesus macaques. PLoS One. 2014;9(2):e89300.

143. Ouattara LA, Barnable P, Mawson P, et al. MIV-150-containing intravaginal rings protect macaque vaginal explants against SHIV-RT infection. Antimicrob Agents Chemother. 2014;58(5):2841-2848.

144. Villegas G, Calenda G, Ugaonkar S, et al. A novel microbicide/ contraceptive intravaginal ring protects macaque genital mucosa against SHIV-RT infection ex vivo. PLoS One. 2016;11(7):e0159332.

145. Aravantinou M, Singer R, Derby N, et al. The nonnucleoside reverse transcription inhibitor MIV-160 delivered from an intravaginal ring, but not from a carrageenan gel, protects against simian/human immunodeficiency virus-RT Infection. AIDS Res Hum Retroviruses. 2012;28(11):1467-1475.

146. McConville C, Major I, Friend DR, Clark MR, Malcolm RK. Development of a UC781 releasing polyethylene vinyl acetate vaginal ring. Drug Deliv Transl Res. 2012;2(6):489-497.

147. McConville C, Smith JM, McCoy CF, et al. Lack of in vitro-in vivo correlation for a UC781-releasing vaginal ring in macaques. Drug Deliv Transl Res. 2015;5(1):27-37.

148. Fetherston SM, Geer L, Veazey RS, et al. Partial protection against multiple RT-SHIV162P3 vaginal challenge of rhesus macaques by a silicone elastomer vaginal ring releasing the NNRTI MC1220. $J$ Antimicrob Chemother. 2013;68(2):394-403. 
149. Gupta KM, Pearce SM, Poursaid AE, et al. Polyurethane intravaginal ring for controlled delivery of dapivirine, a nonnucleoside reverse transcriptase inhibitor of HIV-1. J Pharm Sci. 2008;97(10):4228-4239.

150. Devlin B, Nuttall J, Wilder S, Woodsong C, Rosenberg Z. Development of dapivirine vaginal ring for HIV prevention. Antiviral Res. 2013; 100 (Suppl):S3-S8.

151. Nel A, Haazen W, Nuttall J, Romano J, Rosenberg Z, van Niekerk N. A safety and pharmacokinetic trial assessing delivery of dapivirine from a vaginal ring in healthy women. AIDS. 2014;28(10):1479-1487.

152. Nel A, Smythe S, Young K, et al. Safety and pharmacokinetics of dapivirine delivery from matrix and reservoir intravaginal rings to HIV-negative women. J Acquir Immune Defic Syndr. 2009;51(4): 416-423.

153. Romano J, Variano B, Coplan P, et al. Safety and availability of dapivirine (TMC120) delivered from an intravaginal ring. AIDS Res Hum Retroviruses. 2009;25(5):483-488.

154. Nel A, Bekker LG, Bukusi E, et al. Safety, acceptability and adherence of dapivirine vaginal ring in a microbicide clinical trial conducted in multiple countries in Sub-Saharan Africa. PLoS One 2016;11(3):e0147743.

155. Palanee-Phillips T, Schwartz K, Brown ER, et al. Characteristics of women enrolled into a randomized clinical trial of dapivirine vaginal ring for HIV-1 prevention. PLoS One. 2015;10(6):e0128857.

156. Baeten JM, Palanee-Phillips T, Brown ER, et al. Use of a vaginal ring containing dapivirine for HIV-1 prevention in women. $N$ Engl J Med. 2016;375(22):2121-2132.

157. das Neves J, Martins JP, Sarmento B. Will dapivirine redeem the promises of anti-HIV microbicides? Overview of product design and clinical testing. Adv Drug Deliv Rev. 2016;103:20-32.

158. Rosenberg ZF, Devlin B. Future strategies in microbicide development. Best Pract Res Clin Obstet Gynaecol. 2012;26(4):503-513.

159. Garg S, Goldman D, Krumme M, Rohan LC, Smoot S, Friend DR. Advances in development, scale-up and manufacturing of microbicide gels, films, and tablets. Antiviral Res. 2010;88 (Suppl 1):S19-S29.

160. Rohan LC, Devlin B, Yang H. Microbicide dosage forms. Curr Top Microbiol Immunol. 2014;383:27-54.

161. Joshi SN, Katti U, Godbole S, et al. Phase I safety study of Praneem polyherbal vaginal tablet use among HIV-uninfected women in Pune, India. Trans R Soc Trop Med Hyg. 2005;99(10):769-774.

162. Joglekar NS, Joshi SN, Navlakha SN, Katti UR, Mehendale SM. Acceptability of praneem polyherbal vaginal tablet among HIV uninfected women \& their male partners in Pune, India - Phase I study. Indian J Med Res. 2006;123(4):547-552.

163. Joshi SN, Dutta S, Kumar BK, et al. Expanded safety study of Praneem polyherbal vaginal tablet among HIV-uninfected women in Pune, India: a phase II clinical trial report. Sex Transm Infect. 2008;84(5): 343-347.

164. Joglekar NS, Joshi SN, Deshpande SS, Parkhe AN, Katti UR, Mehendale SM. Acceptability and adherence: findings from a Phase II study of a candidate vaginal microbicide, 'praneem polyherbal tablet', in Pune, India. Trans R Soc Trop Med Hyg. 2010;104(6):412-415.

165. Pereira LE, Clark MR, Friend DR, et al. Pharmacokinetic and safety analyses of tenofovir and tenofovir-emtricitabine vaginal tablets in pigtailed macaques. Antimicrob Agents Chemother. 2014;58(5): 2665-2674.

166. McConville C, Major I, Devlin B, Brimer A. Development of a multi-layered vaginal tablet containing dapivirine, levonorgestrel and acyclovir for use as a multipurpose prevention technology. Eur $J$ Pharm Biopharm. 2016;104:171-179.

167. Woolfson AD, Umrethia ML, Kett VL, Malcolm RK. Freeze-dried, mucoadhesive system for vaginal delivery of the HIV microbicide, dapivirine: optimisation by an artificial neural network. Int J Pharm. 2010;388(1-2):136-143.

168. Rastogi R, Teller RS, Mesquita PM, Herold BC, Kiser PF. Osmotic pump tablets for delivery of antiretrovirals to the vaginal mucosa. Antiviral Res. 2013;100(1):255-258.
169. Akil A, Parniak MA, Dezzuitti CS, et al. Development and Characterization of a Vaginal Film Containing Dapivirine, a Nonnucleoside Reverse Transcriptase Inhibitor (NNRTI), for prevention of HIV-1 sexual transmission. Drug Deliv Transl Res. 2011;1(3): 209-222.

170. Fan MD, Kramzer LF, Hillier SL, Chang JC, Meyn LA, Rohan LC. Preferred physical characteristics of vaginal film microbicides for HIV prevention in Pittsburgh women. Arch Sex Behav. 2016;46(4): 1111-1119.

171. Roddy RE, Zekeng L, Ryan KA, Tamoufé U, Weir SS, Wong EL. A controlled trial of nonoxynol 9 film to reduce male-to-female transmission of sexually transmitted diseases. N Engl J Med. 1998;339(8): 504-510.

172. Rustomjee R, Abdool Karim Q, Abdool Karim SS, Laga M, Stein Z. Phase 1 trial of nonoxynol-9 film among sex workers in South Africa. AIDS. 1999;13(12):1511-1515.

173. Garg S, Vermani K, Garg A, Anderson RA, Rencher WB, Zaneveld LJ. Development and characterization of bioadhesive vaginal films of sodium polystyrene sulfonate (PSS), a novel contraceptive antimicrobial agent. Pharm Res. 2005;22(4):584-595.

174. Cole AM, Patton DL, Rohan LC, et al. The formulated microbicide RC-101 was safe and antivirally active following intravaginal application in pigtailed macaques. PLoS One. 2010;5(11):e15111.

175. Ghosal K, Ranjan A, Bhowmik BB. A novel vaginal drug delivery system: anti-HIV bioadhesive film containing abacavir. J Mater Sci Mater Med. 2014;25(7):1679-1689.

176. Ghosal K, Hazra BT, Bhowmik BB, Thomas S. Formulation development, physicochemical characterization and in vitro-in vivo drug release of vaginal films. Curr HIV Res. 2016;14(4):295-306.

177. Zhang W, Parniak MA, Sarafianos SG, Cost MR, Rohan LC. Development of a vaginal delivery film containing EFdA, a novel anti-HIV nucleoside reverse transcriptase inhibitor. Int J Pharm. 2014;461(1-2): 203-213.

178. Zhang W, Hu M, Shi Y, et al. Vaginal microbicide film combinations of two reverse transcriptase inhibitors, EFdA and CSIC, for the prevention of HIV-1 sexual transmission. Pharm Res. 2015;32(9): 2960-2972.

179. Bunge KE, Dezzutti CS, Rohan LC, et al. A Phase 1 trial to assess the safety, acceptability, pharmacokinetics, and pharmacodynamics of a novel dapivirine vaginal film. J Acquir Immune Defic Syndr. 2016; 71(5):498-505.

180. Robinson JA, Marzinke MA, Bakshi RP, et al. Comparison of dapivirine vaginal gel and film formulation pharmacokinetics and pharmacodynamics (FAME 02B). AIDS Res Hum Retroviruses. 2017; 33(4):339-346.

181. Ham AS, Rohan LC, Boczar A, Yang L, W Buckheit K, Buckheit RW Jr. Vaginal film drug delivery of the pyrimidinedione IQP-0528 for the prevention of HIV infection. Pharm Res. 2012;29(7):1897-1907.

182. Grammen C, Van den Mooter G, Appeltans B, et al. Development and characterization of a solid dispersion film for the vaginal application of the anti-HIV microbicide UAMC01398. Int J Pharm. 2014; 475(1-2):238-244.

183. das Neves J, Nunes R, Rodrigues F, Sarmento B. Nanomedicine in the development of anti-HIV microbicides. Adv Drug Deliv Rev. 2016; 103:57-75.

184. Whaley KJ, Hanes J, Shattock R, Cone RA, Friend DR. Novel approaches to vaginal delivery and safety of microbicides: biopharmaceuticals, nanoparticles, and vaccines. Antiviral Res. 2010;88 (Suppl 1): S55-S66.

185. Mallipeddi R, Rohan LC. Nanoparticle-based vaginal drug delivery systems for HIV prevention. Expert Opin Drug Deliv. 2010;7(1): $37-48$.

186. Lara HH, Ixtepan-Turrent L, Garza-Treviño EN, Rodriguez-Padilla C. PVP-coated silver nanoparticles block the transmission of cell-free and cell-associated HIV-1 in human cervical culture. J Nanobiotechnology. 2010;8:15. 
187. du Toit LC, Pillay V, Choonara YE. Nano-microbicides: challenges in drug delivery, patient ethics and intellectual property in the war against HIV/AIDS. Adv Drug Deliv Rev. 2010;62(4-5): $532-546$.

188. Lara HH, Ixtepan-Turrent L, Garza Treviño EN, Singh DK. Use of silver nanoparticles increased inhibition of cell-associated HIV-1 infection by neutralizing antibodies developed against HIV-1 envelope proteins. J Nanobiotechnology. 2011;9:38.

189. Alukda D, Sturgis T, Youan BB. Formulation of tenofovir-loaded functionalized solid lipid nanoparticles intended for HIV prevention. J Pharm Sci. 2011;100(8):3345-3356.

190. das Neves J, Michiels J, Ariën KK, et al. Polymeric nanoparticles affect the intracellular delivery, antiretroviral activity and cytotoxicity of the microbicide drug candidate dapivirine. Pharm Res. 2012;29(6):1468-1484.

191. das Neves J, Araújo F, Andrade F, et al. In vitro and ex vivo evaluation of polymeric nanoparticles for vaginal and rectal delivery of the anti-HIV drug dapivirine. Mol Pharm. 2013;10(7):2793-2807.

192. das Neves J, Sarmento B. Precise engineering of dapivirine-loaded nanoparticles for the development of anti-HIV vaginal microbicides. Acta Biomater. 2015;18:77-87.

193. Lai WF, He ZD. Design and fabrication of hydrogel-based nanoparticulate systems for in vivo drug delivery. J Control Release. 2016; 243:269-282.

194. Meng J, Sturgis TF, Youan BB. Engineering tenofovir loaded chitosan nanoparticles to maximize microbicide mucoadhesion. Eur J Pharm Sci. 2011;44(1-2):57-67.

195. Meng J, Zhang T, Agrahari V, Ezoulin MJ, Youan BB. Comparative biophysical properties of tenofovir-loaded, thiolated and nonthiolated chitosan nanoparticles intended for HIV prevention. Nanomedicine (Lond). 2014;9(11):1595-1612.

196. das Neves J, Rocha CM, Gonçalves MP, et al. Interactions of microbicide nanoparticles with a simulated vaginal fluid. Mol Pharm. 2012; 9(11):3347-3356.

197. das Neves J, Araújo F, Andrade F, Amiji M, Bahia MF, Sarmento B. Biodistribution and pharmacokinetics of dapivirine-loaded nanoparticles after vaginal delivery in mice. Pharm Res. 2014;31(7): 1834-1845.

198. Yang S, Chen Y, Gu K, et al. Novel intravaginal nanomedicine for the targeted delivery of saquinavir to CD4+ immune cells. Int $J$ Nanomedicine. 2013;8:2847-2858.

199. Zhang T, Sturgis TF, Youan BB. pH-responsive nanoparticles releasing tenofovir intended for the prevention of HIV transmission. Eur J Pharm Biopharm. 2011;79(3):526-536.

200. Agrahari V, Zhang C, Zhang T, et al. Hyaluronidase-sensitive nanoparticle templates for triggered release of HIV/AIDS microbicide in vitro. AAPS J. 2014;16(2):181-193.

201. Destache CJ, Mandal S, Yuan Z, et al. Topical tenofovir disoproxil fumarate nanoparticles prevent HIV-1 vaginal transmission in a humanized mouse model. Antimicrob Agents Chemother. 2016;60(6):3633-3639.

202. das Neves J, Sarmento B. Antiretroviral drug-loaded nanoparticlesin-films: a new option for developing vaginal microbicides? Expert Opin Drug Deliv. 2017;14(4):449-452.

203. Gu J, Yang S, Ho EA. Biodegradable film for the targeted delivery of siRNA-loaded nanoparticles to vaginal immune cells. Mol Pharm. 2015;12(8):2889-2903.

204. Cunha-Reis C, Machado A, Barreiros L, et al. Nanoparticles-in-film for the combined vaginal delivery of anti-HIV microbicide drugs. J Control Release. 2016;243:43-53.

205. Machado A, Cunha-Reis C, Araújo F, et al. Development and in vivo safety assessment of tenofovir-loaded nanoparticles-in-film as a novel vaginal microbicide delivery system. Acta Biomater. 2016;44: 332-340.

206. Srinivasan P, Zhang J, Martin A, et al. Safety and pharmacokinetics of quick-dissolving polymeric vaginal films delivering the antiretroviral IQP-0528 for preexposure prophylaxis. Antimicrob Agents Chemother. 2016;60(7):4140-4150.
207. Blakney AK, Ball C, Krogstad EA, Woodrow KA. Electrospun fibers for vaginal anti-HIV drug delivery. Antiviral Res. 2013;100 (Suppl): S9-S16.

208. Chou SF, Carson D, Woodrow KA. Current strategies for sustaining drug release from electrospun nanofibers. J Control Release. 2015; 220(Pt B):584-591.

209. Ball C, Woodrow KA. Electrospun solid dispersions of Maraviroc for rapid intravaginal preexposure prophylaxis of HIV. Antimicrob Agents Chemother. 2014;58(8):4855-4865.

210. Blakney AK, Krogstad EA, Jiang YH, Woodrow KA. Delivery of multipurpose prevention drug combinations from electrospun nanofibers using composite microarchitectures. Int J Nanomedicine. 2014;9:2967-2978.

211. Krogstad EA, Woodrow KA. Manufacturing scale-up of electrospun poly(vinyl alcohol) fibers containing tenofovir for vaginal drug delivery. Int J Pharm. 2014;475(1-2):282-291.

212. Agrahari V, Meng J, Ezoulin MJ, et al. Stimuli-sensitive thiolated hyaluronic acid based nanofibers: synthesis, preclinical safety and in vitro anti-HIV activity. Nanomedicine (Lond). 2016;11(22):2935-2958.

213. Ball C, Chou SF, Jiang Y, Woodrow KA. Coaxially electrospun fiber-based microbicides facilitate broadly tunable release of maraviroc. Mater Sci Eng C Mater Biol Appl. 2016;63:117-124.

214. Grooms TN, Vuong HR, Tyo KM, et al. Griffithsin-modified electrospun fibers as a delivery scaffold to prevent HIV infection. Antimicrob Agents Chemother. 2016;60(11):6518-6531.

215. Rademacher T, Sack M, Arcalis E, et al. Recombinant antibody 2 G12 produced in maize endosperm efficiently neutralizes HIV-1 and contains predominantly single-GlcNAc N-glycans. Plant Biotechnol J. 2008;6(2):189-201.

216. Fernández Romero JA, Gilb PI, Ré V, Robbiani M, Paglini G. Microbicidas para la prevención de infecciones de transmisión sexual: estado actual y estrategias para la evaluación preclínica de nuevos candidatos. [Microbicides for preventing sexually transmitted infections: current status and strategies for preclinical evaluation of new candidates]. Rev Argent Microbiol. 2014;46(3):256-268. Spanish.

217. Liu X, Lagenaur LA, Simpson DA, et al. Engineered vaginal lactobacillus strain for mucosal delivery of the human immunodeficiency virus inhibitor cyanovirin-N. Antimicrob Agents Chemother. 2006;50(10):3250-3259.

218. Brichacek B, Lagenaur LA, Lee PP, Venzon D, Hamer DH. In vivo evaluation of safety and toxicity of a Lactobacillus jensenii producing modified cyanovirin- $\mathrm{N}$ in a rhesus macaque vaginal challenge model. PLoS One. 2013;8(11):e78817.

219. Lagenaur LA, Sanders-Beer BE, Brichacek B, et al. Prevention of vaginal SHIV transmission in macaques by a live recombinant Lactobacillus. Mucosal Immunol. 2011;4(6):648-657.

220. Marcobal A, Liu X, Zhang W, et al. Expression of human immunodeficiency virus type 1 neutralizing antibody fragments using human vaginal Lactobacillus. AIDS Res Hum Retroviruses. 2016;32(10-11): 964-971.

221. Akil A, Devlin B, Cost M, Rohan LC. Increased Dapivirine tissue accumulation through vaginal film codelivery of dapivirine and tenofovir. Mol Pharm. 2014;11(5):1533-1541.

222. Fetherston SM, Boyd P, McCoy CF, et al. A silicone elastomer vaginal ring for HIV prevention containing two microbicides with different mechanisms of action. Eur J Pharm Sci. 2013;48(3):406-415.

223. van der Straten A, Panther L, Laborde N, et al. Adherence and acceptability of a multidrug vaginal ring for HIV prevention in a Phase I study in the United States. AIDS Behav. 2016;20(11):2644-2653.

224. Chen BA, Panther L, Marzinke MA, et al. Phase 1 safety, pharmacokinetics, and pharmacodynamics of dapivirine and maraviroc vaginal rings: a double-blind randomized trial. J Acquir Immune Defic Syndr. 2015;70(3):242-249.

225. Moss JA, Butkyavichene I, Churchman SA, et al. Combination podintravaginal ring delivers antiretroviral agents for HIV prophylaxis: pharmacokinetic evaluation in an ovine model. Antimicrob Agents Chemother. 2016;60(6):3759-3766. 
226. Ramanathan R, Jiang Y, Read B, Golan-Paz S, Woodrow KA. Biophysical characterization of small molecule antiviral-loaded nanolipogels for HIV-1 chemoprophylaxis and topical mucosal application. Acta Biomater. 2016;36:122-131.
227. Date AA, Shibata A, Goede M, et al. Development and evaluation of a thermosensitive vaginal gel containing raltegravir+efavirenz loaded nanoparticles for HIV prophylaxis. Antiviral Res. 2012;96(3): $430-436$.

\section{Publish your work in this journal}

Drug Design, Development and Therapy is an international, peerreviewed open-access journal that spans the spectrum of drug design and development through to clinical applications. Clinical outcomes, patient safety, and programs for the development and effective, safe, and sustained use of medicines are the features of the journal, which has also been accepted for indexing on PubMed Central. The manuscript management system is completely online and includes a very quick and fair peer-review system, which is all easy to use. Visit http://www.dovepress.com/testimonials.php to read real quotes from published authors.

Submit your manuscript here: http://www.dovepress.com/drug-design-development-and-therapy-journal 